This document is published in:

Review of Economic Dynamics (2009), 12 (1), 147-167. DOI: http://dx.doi.org/10.1016/j.red.2008.06.001

(c) 2008 Elsevier Inc. 


\title{
Delaying retirement in Spain
}

\author{
Javier Díaz-Giménez ${ }^{\mathrm{a}, \mathrm{b}}$, Julián Díaz-Saavedra ${ }^{\mathrm{c}, *}$ \\ a Department of Economics, Universidad Carlos III de Madrid, Spain \\ b CAERP, Spain

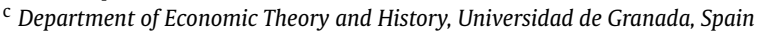

JEL classification:

C68

H55

J26

Keywords:

Computable general equilibrium

Social security reform

Retirement

\begin{abstract}
A B S T R A C T
We study the reform of the Spanish public pension system in a multiperiod, general equilibrium, overlapping generations model economy populated by heterogeneous households. Our households differ in their place of birth, in their age, in their education and, endogenously, in their employment status, in their wealth, and in their pension entitlements. They receive a stochastic endowment of efficiency labor units each period. And they face a disability risk and a survival risk. They understand the link between the payroll taxes that they pay and the public pensions that they receive. And they decide how much to consume and to work, and when to retire from the labor force. We calibrate this economy to Spanish data, and we use it to study the consequences of delaying three years the statutory retirement ages in 2010. We find this reform is sufficient to solve the sustainability problems that plague the current Spanish public pension system. Our model economy predicts that under the current rules, the pension system fund will run out in 2028 and in the reformed economy it will last until 2050. We also find that it is moderately expansionary, and that it improves social welfare from the year 2015 onwards. We conclude that policymakers should seriously consider delaying the statutory retirement ages in Spain sometime in the near future.
\end{abstract}

\section{Introduction}

The financial viability of pay-as-you-go pension systems is being questioned for two main reasons: the aging of the populations and the tendency of workers to retire younger. Consequently the retiree to worker ratios of many developed economies will increase substantially in the next few decades. And many of the current unfunded pension systems will go bankrupt. Another trend that affects the financial situation of unfunded pensions systems is the increased educational attainment of workers. This increase affects the sustainability of pension systems in two ways: because more educated workers pay higher payroll taxes during their working lives, and because they collect higher pensions when they retire.

The purpose of this article is to study the consequences for the Spanish economy of delaying three years the statutory retirement ages in the year 2010. We do so endogenizing the retirement decision and taking into account the demographic and the educational transitions, both of which are particularly severe in the Spanish case. We find that this reform extends the financial viability of the Spanish public pension system for 23 years, and that it improves social welfare from 2015 onwards.

The Spanish demographic transition. In 1997 in Spain there were 23 people aged 65 or older for every hundred workingage people. According to the projections of the Spanish Instituto Nacional de Estadistica, by the year 2050 this number will

\footnotetext{
* Corresponding author at: Universidad de Granada, Department of Economic Theory and History, Campus Cartuja s/n, Granada, Spain.

E-mail addresses: kueli@eco.uc3m.es (J. Díaz-Giménez), julianalbertodiaz@ugr.es (J. Díaz-Saavedra).
} 
have increased to no less than $56 .{ }^{1}$ This change is due both to an increase in life-expectancy and to a substantial reduction in Spanish birth-rates. In 2004 the life expectations of Spanish males and females were 76.6 and 83.3 years. By the year 2050 these numbers are expected to be 80.9 and 87.0. In contrast, between 1957 and 1977 the average number of children per fertile woman was 2.8. Since 1980 this number has decreased continuously, and in 1998 it was only 1.16 . As we show in this article, these demographic changes make the current pay-as-you-go Spanish public pension system completely unsustainable.

Early retirement in Spain. In 1970 the participation rate of Spanish male workers in the 55-64 age cohort was 84.2 percent according to Conde-Ruiz and Galasso (2003). By the year 2000 this rate had fallen to only 60.3 percent. This substantial decline was partly due to a reduction of the average retirement age of almost four years during the same period-from 65.2 years in 1970 to 61.4 in 1995 according to Blöndal and Scarpetta (1997). The tendency to retire early increases the retiree to worker ratios even further. And it places an additional financial burden on the Spanish public pension system.

The Spanish educational transition. In 1977 in Spain only about 9 percent of the working-age people had completed high school and only about 3 percent had completed college. Twenty years later, these shares were 24 percent and 13 percent. And in the year 2050 they are projected to be 38 percent and 24 percent, according to Meseguer (2001). This large educational transition has also large potential implications for the sustainability of the Spanish pay-as-you-go pension system. ${ }^{2}$

The model economy. We quantify the economic consequences of delaying retirement using a multiperiod, general equilibrium, overlapping generations model economy which is populated by heterogeneous households, and which we calibrate to Spanish data. Our model economy combines various features of similar model economies in the public pensions literature.

First, our model economy is populated by natives and immigrants as in Rojas (2005). This feature is important because in the last few years Spain has received large flows of immigrants that are projected to continue in the future. ${ }^{3}$ These flows change the worker to retiree ratios and are potentially important for the sustainability of the Spanish public pension system. Second, our households differ in their education levels as in Cubeddu (1998). This feature allows us to model the Spanish educational transition and to study its consequences for the sustainability of the pension system. It is also important because early retirement behavior is strongly influenced by educational attainment. ${ }^{4}$

Third, our households face stochastic lifetimes as in Hubbard and Judd (1987). This feature allows us to consider the significant increase in life-expectancy projected for the Spanish economy, and to model the longevity insurance role of pension systems. Fourth, our households face an uninsurable idiosyncratic shock to their endowments of efficiency labor units as in Conesa and Krueger (1999). This feature allows us to account for the income and earnings distributions of the Spanish economy. It also helps us to account for the participation rates and the retirement ages of Spanish elderly workers.

Fifth, our households face the possibility of becoming disabled and receiving a disability pension. Rust and Phelan (1997) introduce this feature in a partial equilibrium model. We model disability pensions explicitly because they are an alternative route to early retirement in Spain. ${ }^{5}$ Sixth, our households take into account the link between payroll taxes and pensions when making their consumption, savings, and retirement decisions as in Huggett and Ventura (1999). We model this feature because pension entitlements are a sizable part of the compensation of workers, and because they play an important role in the labor decision, specially towards the end of the working-life. Finally, our households decide optimally when to retire as in Sánchez-Martín (2001). This feature endogenizes the numbers and ages of workers and it allows us to account for the tendency of Spanish workers to retire early.

We also model many of the institutional features of the current Spanish public pension system in very much detail. Our model economy pensions replicate the Spanish payroll tax cap, the maximum covered earnings, the minimum and maximum pensions, the penalties for early retirement, the pension fund, and the disability pensions. In addition, the government in our model economy taxes labor income, capital income, and consumption. It spends in public consumption and transfers other than pensions, and it services a stock of public debt. Other important features of our model economy are that it replicates the Lorenz curves of the Spanish earnings and income distributions as reported in Budría and Díaz-Giménez (2006a). And that it accounts for many of the features of the retirement behavior of Spanish workers.

Reform. We study the consequences for the Spanish economy of delaying the first retirement age from 60 to 63 years and the normal retirement age from 65 to 68 years. We assume that this reform is implemented in the year 2010, and that it affects all current workers and disabled households.

Findings. We find that delaying three years the statutory retirement ages is sufficient to solve the severe viability problems that plague the current Spanish pension system. We find that, under the current rules, the Spanish public pension

\footnotetext{
1 The population projections that we consider in this article correspond to the Hypothesis 1 of the Instituto Nacional de Estadística. This hypothesis depicts the most favorable demographic scenario for the sustainability of Spanish pensions because it assumes the highest inflows of immigrants and the smallest increases in life expectancy. Its details can be found at http://www.ine.es/metodologia/t20/t2030251h.htm.

2 See Díaz-Giménez and Díaz-Saavedra (2006) for a detailed analysis of the consequences of the Spanish demographic and educational transitions for the financial viability of the Spanish public pension system.

${ }^{3}$ Under the Hypothesis 1 of its population projections, the Instituto Nacional de Estadística expects that approximately fifteen million immigrants will enter the Spanish economy between 2002 and 2050.

4 See Blöndal and Scarpetta (1997).

5 See Boldrin and Jiménez-Martín (2003) for an elaboration on this argument.
} 
system will start running a deficit in the year 2016, and that the pension fund will run out in the year 2028 . In the reformed economy the first deficit will appear in the year 2030-14 years later-and the pension fund will run out in the year 2050-23 years later. We also find that delaying retirement is moderately expansionary, and that it increases income inequality somewhat. Specifically, in 2013 output is about 1.4 percent larger in the reformed model economy, and by 2060 this difference has stabilized at about 2.8 percent. While the Gini index of income will be 0.403 under the current rules in 2060 , and 0.410 in the reformed economy.

Finally, we compute the welfare costs of delaying retirement under the assumption that the pension deficits are financed raising consumption taxes as needed once the pension fund is exhausted. We find that delaying retirement under these rules brings about a social welfare gain between 2010 and 2060 which is equivalent to 1.34 percent of the present value of aggregate consumption in the benchmark model economy during that period.

Conclusions. We conclude that policymakers should seriously consider delaying the statutory retirement ages in Spain sometime in the near future.

\section{Previous literature}

The study of parametric reforms of pay-as-you-go pension systems threatened by sizeable demographic transitions has been subject of a large body of previous research. In a general equilibrium setup, De Nardi et al. (1999), for instance, study the consequences of delaying two years the statutory retirement age in the United Sates. They find that this reform reduces the size of the fiscal burden, and that the consumption tax rate levied to finance this burden falls from 36.9 to 31.2 percent.

Amongst the general equilibrium studies of pension reforms in Spain, the article that is closest to ours is Sánchez-Martín (2001). He also uses a general equilibrium, multiperiod, overlapping generations model with heterogeneous households that differ in their education. He finds that delaying two years the first and the normal retirement ages reduces the pension system deficit from 6.9 to 4.3 percent of GDP in 2060. The main differences between Sánchez-Martín's article and ours are that he does not endogenize the labor decision, that his households do not face an idiosyncratic labor productivity shock, and that he abstracts from the educational transition and from many details of the Spanish tax and public pension systems. ${ }^{6}$

De Miguel and Montero (2004) study a general equilibrium, multiperiod, overlapping generations model economy populated by households who, like ours, face a survival risk. But, unlike ours, their households differ in their age only. They simulate a reform that delays the normal retirement age from 65 to 70 . They find that the pension payments to output ratio decreases from 13.2 to 9.5 percent in the year 2050 and that the labor income tax rate that is needed to finance the pension system deficit decreases from 19.2 to 13.9 percent in that same year. ${ }^{7}$

Most of the studies of pension reforms in Spain have been either partial equilibrium analyses or accounting models. The findings of these modeling approaches are summarized in Jimeno et al. (2008). Amongst these studies, Boldrin and JiménezMartín (2003) find that delaying three years the statutory retirement ages makes most of the people who now retire at 65 delay their retirement until 68. And that this reform brings about substantial increases in the labor force participation of the elderly. Even though their model economy does not simulate the evolution of the pension system deficit, they conclude that this reform would not be enough to sustain the Spanish public pension system during the next few decades. But this result arises mainly because they abstract from the pension system fund.

Da-Rocha and Lores (2005) use an individual life profile approach to study the consequences of delaying five years the normal retirement age. They implement the reform in 2005, and they find that in 2050 the value of the accumulated pension system debt is reduced from 259 percent of GDP in their benchmark economy to 59 percent of GDP in their reformed economy. The differences between their results and ours arise mainly because the ratio of pension expenditures to GDP is about 26 percent in 2050 in their benchmark model economy. In our model economy and in many of the other articles referenced here this number is sizeably smaller-approximately 18 percent.

Finally, Balmaseda et al. (2006) study the consequences of delaying the mandatory retirement age from 65 to 70 . They use a general accounting approach with no endogenous responses to the policy changes. And they consider various demographic and labor market scenarios. In their most optimistic demographic scenario, they find that in 2050 their reform reduces the present value of the accumulated pension system debt from 182 percent of 2004 GDP to 9.6 percent. And that their reform delays in 28 years the depletion of the pension fund-from 2018 in their benchmark model economy to 2046 in their reformed economy. ${ }^{8}$

\footnotetext{
${ }^{6}$ Specifically, Sánchez-Martín (2001) uses lump-sum taxes to balance the government budget. His payroll tax is uncapped. And he does not model the pension fund, maximum pensions, and disability pensions.

7 Arjona (2000) studies a very similar model economy. The main differences between De Miguel and Montero (2004) and Arjona (2000) are the ways in which they model the demographic transition, and the policy reforms that they analyze.

8 Our results are more optimistic even though we delay the retirement ages in only three years. In our benchmark model economy the pension fund lasts until 2027, and in our reformed model economy until 2050. It would be interesting to study exactly the same reform and to simulate exactly the same demographic and educational transitions using both their methodology and ours. This exercise would allow us to evaluate the importance of endogenizing the decision rules in this type of studies.
} 


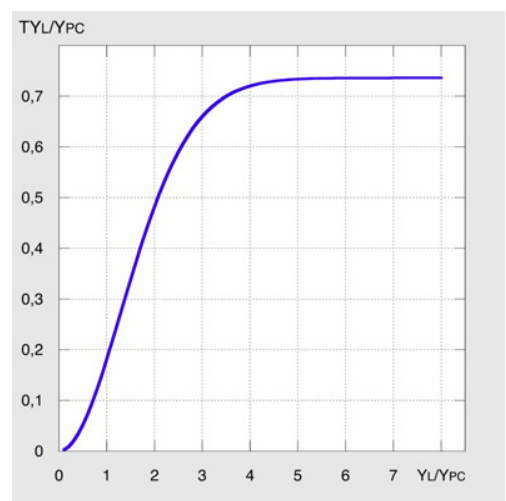

A. The payroll tax in 1997.

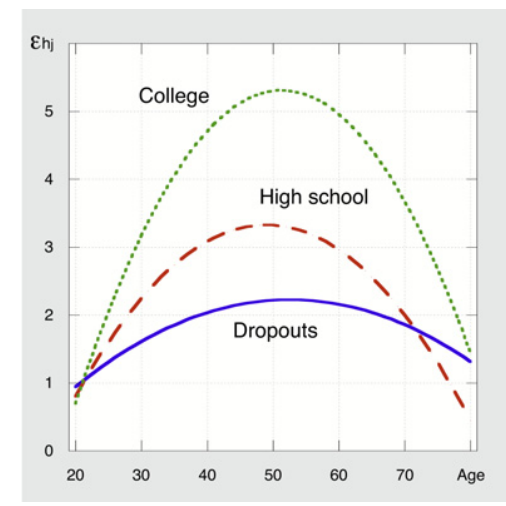

B. The edowment of ELU.

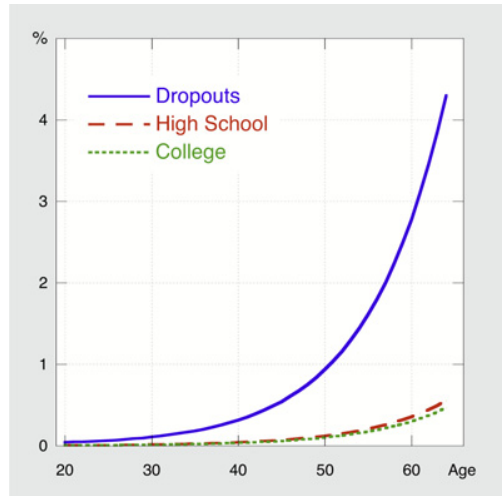

C. The disability risk.

Fig. 1. The payroll tax, the endowment of efficiency labor units and the disability risk.

\section{The model economy}

We study a general equilibrium overlapping generations model economy populated by heterogeneous households. It is made up by a public and a private sector which we describe in turn.

\subsection{The public sector}

The public sector runs a pay-as-you-go public pension system. It collects income and consumption taxes. And it uses their revenues to finance flows of government consumption and of transfers other than pensions, and to service a stock of public debt.

\subsubsection{The public pension system}

The pension system in our model economy replicates in very much detail the main features of the Spanish Régimen General de la Seguridad Social. In 2001 included this regime included 73.9 percent of all Spanish workers. The features of the public pension system in our model economy are the following:

Payroll taxes. The Spanish pension system is financed with a payroll tax on gross labor earnings. The payroll tax is capped and it has a tax-exempt minimum. The payroll tax in our model economy is described by function, $\tau_{s}\left(y_{h, j, t}\right)$, where $y_{h, j, t}$ denotes the gross labor earnings of a worker with education level $h$ who is $j$ years old in period $t$. To characterize the payroll tax, we use the following two-parameter function:

$$
\tau_{s t}\left(y_{h, j, t}\right)=a_{1, t}-\left[a_{1, t}\left(1+a_{2, t} y_{h, j, t}\right)^{-y_{h, j, t}}\right] .
$$

Parameter $a_{1, t}$ determines the maximum contribution. We make it a function of per capita income and since we simulate a growing economy it is time-varying. This functional form allows us to replicate the Spanish payroll tax cap exactly. But it does not allow us to replicate the tax exempt minimum. In Panel A of Fig. 1 we represent the payroll tax function for our chosen values of $a_{1, t}$ and $a_{2, t}$ for 1997.

Retirement pensions. A retiree of age $j$ is entitled to receive a public pension while he is alive. We denote this pension by $b_{t}$. As in the Spanish pension system, we assume that pensions in our model economy are bounded by a minimum pension, which we denote by $\underline{b}_{t}$, and by a maximum pension, which we denote by $\bar{b}_{t}$. We allow these limits to vary with time because we study a growth economy, and because in Spain minimum and maximum pensions are adjusted to keep up with the growth of output. ${ }^{9}$ The pension system rules establish also the first retirement age, which we denote by $R_{0}$, and the normal retirement age, which we denote by $R_{1}$.

To capture the main features of Spanish pensions, we assume that the pensions in our model economy are computed according to the following formula:

$$
b_{t}=\frac{1}{N_{b}}(1.02)^{q}\left(1-\lambda_{j}\right) \phi \sum_{t=j-N_{b}}^{j-1} \min \left\{a_{3, t}, y_{h, j, t}\right\}
$$

where parameter $N_{b}$ denotes the number of consecutive years immediately before retirement that are used to compute the pension. Variable $q$ denotes the number of years that the worker remains in the labor force after reaching the normal

\footnotetext{
9 Formally, maximum and minimum pensions in Spain are adjusted to keep up with inflation. In the last twenty years the Spanish average inflation rate and the average growth rate have been similar.
} 
retirement age. ${ }^{10}$ Function $0 \leqslant \lambda_{j}<1$ denotes the penalty that the households must pay when they opt for early retirement. Parameter $0<\phi<1$ denotes the pension system replacement rate. And parameter $a_{3, t}$ is the maximum covered earnings. As is the case the Spanish economy, our model economy pensions are computed when a worker retires and they are indexed to the rate of growth of output.

The Spanish Régimen General establishes that the penalties for early retirement are a linear function of the retirement age. To replicate this rule, our choice for the early retirement penalty function is the following

$$
\lambda_{j}= \begin{cases}a_{4}-a_{5}\left(j-R_{0}\right) & \text { if } j<R_{1}, \\ 0 & \text { if } j \geqslant R_{1} .\end{cases}
$$

The Spanish replacement rate is a function of the number of years of contributions. In our model economy we abstract from this feature because it would have forced us to include an additional state variable.

Disability pensions. We model disability pensions explicitly for three reasons: because they represent a large share of all Spanish pensions (11.0 percent of all pensions in 1997), because in many cases disability pensions are used as an alternative route to early retirement, ${ }^{11}$ and because most of the data on retirement and pensions lump together old age and disability. In our model economy we model disability as a stochastic process which we describe in Section 3.2.2 below. And we assume that the households who become disabled receive a disability pension which we denote by $b_{d t}$. In accordance with the current Spanish rules, we assume that there is a minimum disability pension which coincides with the minimum retirement pension. And that the disability pensions are 75 percent of the households' retirement claims. Formally, the disability pensions in our model economy are

$$
b_{d t}=\max \left\{\underline{b}_{t}, 0.75 b_{t}\right\} \text {. }
$$

Moreover we assume that after a disabled household reaches the age to retire it can change its disability pension for a retirement pension paying the early retirement penalty if applicable. ${ }^{12}$

The pension system fund. In Spain in 2000 the government created a pension system fund to capitalize the pension system surpluses. To replicate this feature in our model economy, we assume that from 2005 onwards the government moves the pensions and the payroll tax revenues off-budget, and that it operates a pension system fund. ${ }^{13}$ Variable $F_{t}$ denotes the value of this fund at the end of period $t$. We assume that the pension fund is invested in foreign assets, and that these assets obtain an exogenous rate of return, which we denote by $r^{*}$. We make these assumptions to buffer the model economy from the large distortions created by the sizable public pension deficits that are predicted to take place during the Spanish demographic and educational transitions. The fund works as follows: whenever there is a surplus in the pension system, it is invested in the fund, and whenever there is a deficit, it is financed using the fund. In our benchmark model economy we assume that the government borrows as much as necessary to finance any further pension system deficits after the fund is exhausted. And that it pays the same exogenous rate $r^{*}$ on this loans. Therefore, the law of motion of the pension fund is the following:

$$
F_{t}=\left(1+r^{*}\right) F_{t-1}+T_{s t}-P_{t}
$$

where variable $T_{s t}$ denotes the revenues collected by the payroll tax, and variable $P_{t}$ denotes the aggregate retirement and disability pension payments. To characterize completely the law of motion of the pension fund, we must choose the values of $r^{*}$ and of $F_{0}$.

\subsubsection{The government budget}

We choose the tax instruments and the expenditure items of our model economy government to resemble the tax instruments and the expenditure items of the Spanish government.

Revenues. The government in our model economy collects tax revenues using a proportional tax on capital income, which we denote by $\tau_{k t}$, a proportional tax on labor income net of payroll taxes, which we denote by $\tau_{l t}$, and a proportional tax on consumption, which we denote by $\tau_{c t}$. It also issues one period real debt. We denote the beginning-of-period value of this debt by $D_{t}$. Finally, the government confiscates unintentional bequests, which we denote by $E_{t}$.

Outlays. Each period the government in our model economy consumes $G_{t}$ units of goods. It makes exogenous, nonpension, lump-sum transfers to households in an amount of $Z_{t}$. And it repays the principal plus the interest on an endogenous stock of public debt in an amount of $\left(1+r_{t}\right) D_{t}$, where $r_{t}$ denotes the equilibrium interest rate which we define below.

\footnotetext{
10 This late retirement premium was introduced in the 2002 Amendment of the Spanish Public Pension System.

11 See Boldrin and Jiménez-Martín (2003) for an elaboration of this argument.

12 The Spanish rules contemplate a special reduction of the first retirement age for disabled households. The reduction is proportional to the number of years of contributions. We have not included this feature in our model economy for computational reasons.

13 We choose 2005 because that is the first year for which the value of the Spanish fund is readily available.
} 
Budget constraint. Until 2005 when the pension fund is created, the government budget constraint is

$$
G_{t}+Z_{t}+\left(1+r_{t}\right) D_{t}+P_{t}=T_{k t}+T_{l t}+T_{c t}+E_{t}+D_{t+1}+T_{s t}
$$

where $T_{k t}, T_{l t}$, and $T_{c t}$ denote the revenues collected by the capital income tax, the labor income tax, and the consumption tax.

From 2005, when the pension fund starts to operate and the payroll tax revenues and the pension payments are moved off-budget, the government budget described in expression (6) becomes

$$
G_{t}+Z_{t}+\left(1+r_{t}\right) D_{t}=T_{k t}+T_{l t}+T_{c t}+E_{t}+D_{t+1} .
$$

Adding up, it turns out that to characterize the government policy completely in our model economy we must choose the values of a total of 20 parameters.

\subsection{The private sector}

\subsubsection{Firms}

We assume that the firms in our model economy behave competitively in the product and factor markets, that they maximize profits, and that they have free access to a constant returns to scale production technology that can be described by aggregate production function $Y_{t}=F\left(K_{t}, A_{t} L_{t}\right)$. Variable $Y_{t}$ denotes aggregate output, $K_{t}$ denotes aggregate capital, $L_{t}$ denotes the aggregate labor input and $A_{t}$ denotes an exogenous, labor-augmenting productivity factor whose law of motion is $A_{t+1}=(1+\gamma) A_{t}$. We assume that $\gamma>0$ and that the capital stock depreciates geometrically at a constant rate, $0<\delta<1$. We choose a standard Cobb-Douglas production function with capital share $\theta$. Formally,

$$
Y_{t}=K_{t}^{\theta}\left(A_{t} L_{t}\right)^{1-\theta} \text {. }
$$

And we use $r$ and $w$ to denote the rates of return to capital and labor, gross of all taxes.

The profit maximizing behavior of firms implies that factor prices are the corresponding factor marginal productivities. That is,

$$
r_{t}=F_{K}\left(K_{t}, A_{t} L_{t}\right)-\delta
$$

and

$$
w_{t}=F_{L}\left(K_{t}, A_{t} L_{t}\right) .
$$

Notice that in our model economy labor productivity grows for two reasons: because $\gamma>0$, and because as workers become more educated, their endowment of effective labor units increases and they become more productive per unit of time devoted to labor. Notice also that to characterize our technology we must choose the values of 4 parameters.

\subsubsection{Households}

We assume that our model economy is inhabited by continuum of heterogeneous households, which we normalize each period so that its measure is always equal to one. The households differ in their place of birth, $\ell \in \mathcal{L}$, in their education, $h \in H$, in their age, $j \in J$, in their employment status, $s \in S$, in their assets, $a \in \mathcal{A}$, and in their pension claims, $b \in B \cup B^{d}$. Sets $\mathcal{L}, H, J, S, \mathcal{A}, B$, and $B^{d}$ are all finite sets which we describe below. We use $\mu_{\ell, h, j, s, a, b, t}$ to denote the measure of households of type $(\ell, h, j, s, a, b)$ at period $t$, and for convenience, whenever we integrate the measure of households over some dimension, we drop the corresponding subscript.

Place of birth. Households can either be immigrants, and then $\ell=i$, or native to the economy, and then $\ell=n$. Consequently $\mathcal{L}=\{i, n\}$. We assume that a measure $\mu_{i, t}$ of immigrants enters the economy at the beginning of each period, and that this measure is exogenous.

Education. In this article we abstract from the education decision. Instead we assume that the education of both natives and immigrants is determined forever when they enter the economy. We consider three educational levels and, consequently, $H=\{1,2,3\}$. Educational level $h=1$ denotes that the household has dropped out of high school. ${ }^{14}$ Educational level $h=2$ denotes that the household has completed high school but has not completed college. Finally, educational level $h=3$ denotes that the household has completed college.

Age. Both native households and the youngest immigrants enter the economy when they are 20 years old and they live up to a maximum of 100 years. Consequently, $J=\{20,21, \ldots, 100\}$.

Population dynamics. Each period both immigrants and natives face age-dependent and time-varying conditional probabilities of surviving from age $j$ to age $j+1$, which we denote by $\psi_{j, t}$. They also face age-dependent and time-varying

\footnotetext{
14 In this group we include every household that has not completed the compulsory education. Due to the changes in the Spanish educational laws, we define the compulsory studies to be either the Estudios Secundarios Obligatorios, the Graduado Escolar, the Certificado Escolar, or the Bachiller Elemental.
} 
probabilities of bearing offspring, which we denote by $f_{j, t}$. We assume that the survival probabilities and fertility rates of immigrants and natives are the same because independent data for these two population groups are not readily available. Finally, we treat the offspring of immigrants as natives.

These assumptions imply that at the beginning of every period there is a measure $1+n_{t}$ of households in our economy. Variable $n_{t}$ denotes the population growth rate, which we compute as follows:

$$
n_{t}=\mu_{i, t}+\sum_{J}\left[\psi_{j, t-1}+f_{j, t-1}\right] \mu_{j, t-1}-1 .
$$

We normalize the measures of households each period so that the law of motion of $\mu_{j, t}$ is

$$
\mu_{20, t+1}=\frac{1}{\left(1+n_{t}\right)}\left[\mu_{i, 20, t+1}+\sum_{J} f_{j, t} \mu_{j, t}\right]
$$

and

$$
\mu_{j, t+1}=\frac{1}{\left(1+n_{t}\right)}\left[\mu_{i, j, t+1}+\psi_{j-1, t} \mu_{j-1, t}\right]
$$

for each $j>20$.

Employment status. Households in our economy are either workers, disabled or retired. We denote workers by $s \in \mathcal{S}=$ $\left\{s_{1}, s_{1}, \ldots, s_{n}\right\}$, disabled households by $d$, and retirees by $\rho$. Consequently, the set of realizations of the household specific shock is $S=\{\mathcal{S}, d, \rho\}$.

Workers. Each period, each worker receives an endowment of efficiency labor units. This endowment has two components: a deterministic component that depends on the age and the education of the worker, which we denote by $\epsilon_{h, j}$, and a stochastic idiosyncratic component, which we denote by $s$.

To model the deterministic component of the endowment of efficiency labor units we use quadratic functions of the following form:

$$
\epsilon_{h, j}=a_{6, h}+a_{7, h} j-a_{8, h} j^{2} .
$$

This functional form captures the concavity of the workers' productivity profiles over their life-cycle in a very parsimonious way. We represent these functions in Panel B of Fig. 1. Since we consider three educational levels, to characterize these functions we must choose the values of 9 parameters.

We assume that the process on the stochastic component takes three values. That is, we assume that $\mathcal{S}=\left\{s_{1}, s_{2}, s_{3}\right\}$. We also assume that it follows a finite state Markov chain that is independent and identically distributed across workers, and whose conditional transition probability matrix is $\Gamma=\operatorname{Pr}\left\{s_{t+1}=s^{\prime} \mid s_{t}=s\right\}$, where $s$ and $s^{\prime} \in \mathcal{S}$. We make these assumptions because it turns our that three states are sufficient to account for the Lorenz curves of the Spanish distributions of income and labor earnings in sufficient detail, and because we want to keep this process as parsimonious as possible. These choices imply that to specify the process on $s$ we must choose the values of 12 parameters: the 3 values of the realizations and the 9 values of the conditional transition probabilities of matrix $\Gamma$.

Disability. We assume that workers also face an age and education-dependent disability risk. Specifically, a worker of type $(h, j)$ faces a probability $\varphi_{h, j, t}$ of being disabled from age $j+1$ onwards. When a household receives a disability shock we assume that it exits the labor market forever. Consequently, disabled households receive no endowment of efficiency labor units. When a disabled household reaches the first retirement age it decides whether to change the disability pension for the retirement pension to which it is entitled.

To determine the values of the $\varphi_{h, j, t}$ we proceed in two stages. First we model the aggregate probability of becoming disabled at age $j+1$, which we denote by $p_{j}$. We assume that $p_{j}$ is determined by the following function:

$$
p_{j}=\mathrm{e}^{\left(a_{9}+a_{10} \times j\right)} \text {. }
$$

We make this choice because, according to the Boletín de Estadísticas Laborales (2002), the number of disabled people in Spain increases more than proportionally with age. Then, to compute the age and education-dependent disability risk, $\varphi_{h, j, t}$, we solve the following system of equations:

$$
\left\{\begin{array}{l}
p_{j} \mu_{j, t}=\sum_{h} \varphi_{h, j, t} \mu_{h, j, t} \\
\varphi_{2, j, t}=a_{11} \varphi_{1, j, t} \\
\varphi_{3, j, t}=a_{12} \varphi_{1, j, t}
\end{array}\right.
$$

From 1997 we assume that the $\varphi_{h, j, t}$ become time-invariant at their 1997 values. We make these choices because, according to the Instituto Nacional de Estadística, the number of disabled households differs significantly across educational types. ${ }^{15}$

15 The data on disability can be found at http://www.mtas.es/estadisticas. 
Consequently, to characterize the disability probabilities, we must choose the values of 4 parameters. We represent our chosen $\varphi_{h, j, t}$ for 1997 onwards in Panel C of Fig. 1.

Retirement. Finally, workers of age $R_{0}$ or older observe the realization of $s$ and they decide whether to retire from the labor force forever and collect their retirement pensions. Naturally, retirees receive no endowments of efficiency labor units.

Assets. We assume also that the households in our model economy cannot borrow. Since leisure is an argument of the households' utility function, this borrowing constraint can be interpreted as a solvency constraint that prevents the households from going bankrupt in every state of the world. These restrictions give the households a precautionary motive to save. They do so accumulating real assets, which we denote by $a_{t}$, and which take the form of either productive capital or government debt. For computational reasons we restrict the asset holdings to belong to the discrete set $\mathcal{A}=\left\{a_{1}, a_{2}, \ldots, a_{n}\right\}$. We choose the dimension of set $\mathcal{A}$ to be 50 points. We assume that $a_{1}=0$, that $a_{n}=155$, and that the spacing between points in set $\mathcal{A}$ is increasing. ${ }^{16}$

Pension claims. For computational reasons we restrict the retirement pension claims to belong to the discrete set $B=$ $\left\{b_{1 t}, b_{2 t}, \ldots, b_{n t}\right\}$, where $b_{1 t}=\underline{b}_{t}$ and $b_{n t}=\bar{b}_{t}$. For identical reasons, we also restrict the disability pension claims to belong to the discrete set $B^{d}=\left\{b_{d 1 t}, b_{d 2 t}, \ldots, b_{d n t}\right\}$, where $b_{d 1 t}=\underline{b}_{t}$ and $b_{d i t}=0.75 b_{i t}$ for every $i \geqslant 2$. We choose the dimensions of sets $B$ and $B^{d}$ to be 10 points, and we assume that every point in sets $B$ and $B^{d}$ is equally spaced.

Market arrangements. We assume that there are no insurance markets for the stochastic component of the endowment shock. This is a key feature of this class of model worlds. When insurance markets are allowed to operate, every household of the same birthplace, age, and education level is alike and the income and wealth distributions in our model economy become much more disperse.

Preferences. We assume that the households in our model economy have identical preferences that can be described by the following expected utility function:

$$
E\left\{\sum_{j=20}^{100} \beta^{j-20} \psi_{j, t}\left[c_{h, j, t}^{\alpha}\left(1-l_{h, j, t}\right)^{(1-\alpha)}\right]^{1-\sigma} /(1-\sigma)\right\}
$$

where $0<\beta$ denotes the time discount factor, $c_{h, j, t}$ denotes consumption and $l_{h, j, t}$ denotes labor. Consequently, $1-l_{h, j, t}$ is the amount of time that the households allocate to non-market activities. The form of the utility function is standard in the literature, and to characterize it we must choose the values of 3 parameters.

The households' decision problem. The households in our model economy solve the following decision problem:

$$
\max E\left\{\sum_{j=20}^{100} \beta^{j-20} \psi_{j, t}\left[c_{h, j, t}^{\alpha}\left(1-l_{h, j, t}\right)^{(1-\alpha)}\right]^{1-\sigma} /(1-\sigma)\right\}
$$

subject to

$$
c_{h, j, t}+a_{h, j, t+1}+\tau_{h, j, t}=\left(1+r_{t}\right) a_{h, j, t}+z_{t}+w_{t} \epsilon_{h, j} s_{t} l_{h, j, t} I_{s \in \mathcal{S}}+b_{d t} I_{s=d}+\left(1-\lambda_{j}\right) b_{t} I_{s^{\prime}=\rho}
$$

and to

$$
\tau_{h, j, t}=\tau_{c t} c_{h, j, t}+\tau_{k t} r_{t} a_{h, j, t}+\tau_{l t}\left[y_{h, j, t}-\tau_{s t}\left(y_{h, j, t}\right) I_{j \leqslant R_{1}}\right]+\tau_{s t}\left(y_{h, j, t}\right) I_{j \leqslant R_{1}} .
$$

In these two expressions $a_{h, j, t+1}$ denotes the end-of-period assets, $z_{t}$ denotes the non-pension transfers, $y_{h, j, t}$ denotes the labor income which is equal to $y_{h, j, t}=w_{t} \epsilon_{h, j} s_{t} l_{h, j, t}$, and the indicator functions $I_{s \in \mathcal{S}}, I_{s=d}, I_{s^{\prime}=\rho}$, and $I_{j \leqslant R_{1}}$, indicate whether the household is a worker, is disabled, or is retired, and whether it was $R_{1}$ years old or less after year $2001 .{ }^{17}$

When the households are between 20 and $\left(R_{0}-1\right)$ years old, they cannot retire and they decide how much to consume, to save, and to work taking into account how these decisions affect their future pension claims. When workers reach age $R_{0}$, they decide whether to retire. When disabled households reach age $R_{0}$, they decide whether to collect the disability pension or the retirement pension. Finally, when workers reach age 84 they are forced to retire.

When a household chooses to work after age $R_{0}$ it earns the product of its labor and it avoids the early retirement penalties. Its costs are the forgone leisure and the foregone pension. But there is also another effect: the change in its pension claim. This change could be either a benefit or a cost depending on the household's current endowment of efficiency labor units and on its current pension entitlement. Minimum retirement pensions play a large role in the retirement decision because they are exempt from the early retirement penalties. Consequently, households with small enough pension claims choose to retire at the first retirement age.

\footnotetext{
${ }^{16}$ In overlapping generation models with finite lives and no altruism there is no need to impose an upper bound for set $\mathcal{A}$ since households who reach the maximum age will optimally consume all their assets. İmrohoroğlu et al. (1995) make a similar point.

17 In 2002 the Spanish public pension system was amended and workers older than $R_{1}$ years were exempted from paying payroll taxes. We use indicator function $I_{j \leqslant R_{1}}$ to replicate this feature of the Spanish pension system.
} 


\section{Definition of equilibrium}

Let $\ell \in \mathcal{L}, h \in H, j \in J, s \in S, a \in \mathcal{A}$, and $b \in B \cup B^{d}$, and let $\mu_{\ell, h, j, s, a, b, t}$ be a probability measure defined on $\Re=$ $\mathcal{L} \times J \times H \times S \times \mathcal{A} \times B{ }^{18}$ Then, given initial conditions $\mu_{0}, A_{0}, D_{0}, E_{0}, F_{0}$, and $K_{0}$, a competitive equilibrium for this economy is a government policy, $\left\{G_{t}, P_{t}, Z_{t}, T_{c t}, T_{k t}, T_{l t}, T_{s t}, D_{t+1}, E_{t+1}, F_{t+1}\right\}_{t=0}^{\infty}$, a household policy, $\left\{c_{t}(h, j, s, a, b), l_{t}(h, j, s, a, b)\right.$, $\left.a_{t+1}(h, j, s, a, b)\right\}_{t=0}^{\infty}$, a sequence of measures, $\left\{\mu_{t+1}\right\}_{t=0}^{\infty}$, a vector of factor prices, $\left\{r_{t}, w_{t}\right\}_{t=0}^{\infty}$, a vector of macroeconomic aggregates, $\left\{K_{t+1}, L_{t}\right\}_{t=0}^{\infty}$, a function, $Q$, and a number, $r^{*}$, such that the following conditions hold:

(i) Factor inputs, pension payments, transfers, tax revenues, and accidental bequests are obtained aggregating over the model economy households as follows:

$$
\begin{aligned}
& \left(K_{t+1}+D_{t+1}\right)=\int a_{h, j, t+1} \mathrm{~d} \mu_{t}, \\
& L_{t}=\int \epsilon_{h, j} s_{t} l_{h, j, t} \mathrm{~d} \mu_{t}, \\
& P_{t}=\int\left(b_{t}+b_{d t}\right) \mathrm{d} \mu_{t}, \\
& Z_{t}=\int z_{t} \mathrm{~d} \mu_{t}, \\
& T_{c t}=\int \tau_{c t} c_{h, j, t} \mathrm{~d} \mu_{t}, \\
& T_{k t}=\int \tau_{k t} r_{t} a_{h, j, t} \mathrm{~d} \mu_{t}, \\
& T_{l t}=\int \tau_{l t}\left[y_{h, j, t}-\tau_{s t}\left(y_{h, j, t}\right) I_{j \leqslant R_{1}}\right] \mathrm{d} \mu_{t}, \\
& T_{s t}=\int \tau_{s t}\left(y_{h, j, t}\right) I_{j \leqslant R_{1}} \mathrm{~d} \mu_{t}, \\
& E_{t+1}=\int\left(1-\psi_{j, t}\right)\left(1+r_{t+1}\right) a_{h, j, t+1} \mathrm{~d} \mu_{t},
\end{aligned}
$$

where $y_{h, j, t}=w_{t} \epsilon_{h, j} s_{t} l_{h, j, t}$ and all the integrals are defined over the state space $\Re$.

(ii) The government policy and $r^{*}$ satisfy the law of motion of the pension system fund described in expression (5) and the government budget constraints described in expressions (6) and (7).

(iii) Given, $K_{t}, L_{t}$, and the government policy, the factor prices are the factor marginal productivities defined in expressions (9) and (10). And the household policy solves the households' decision problem defined in expressions (18), (19) and (20).

(iv) The goods market clears:

$$
\int_{\Re} c_{h, j, t} \mathrm{~d} \mu_{t}+K_{t+1}+G_{t}+\left(T_{s t}-P_{t}\right) I_{t>2004}=F\left(K_{t}, A_{t} L_{t}\right)+(1-\delta) K_{t} .
$$

The last term of the left-hand side of this expression is not standard. It states that from 2005 the pension system surpluses are invested in the pension fund and that the pension deficits are financed using the proceeds of the fund. And it would show up as net exports in the standard national income and product accounts. Before that year the pension system surpluses and deficits are consolidated with the other items of the government budget.

(v) The law of motion for $\mu_{t}$ is:

$$
\mu_{t+1}=\int_{\Re} Q_{t} \mathrm{~d} \mu_{t}
$$

Describing function $Q$ formally is complicated because it specifies the transitions of the measure of households along its six dimensions: place of birth, education level, age, employment status, assets holdings, and pension entitlements. An informal description of this function is the following: since the flows of immigrants are exogenous to the model economy, the evolution of $\mu_{i, t}$ is also exogenous. The evolution of $\mu_{h, t}$ is implied by the educational shares of immigrants and native new-entrants, both of which are exogenous. The evolution of $\mu_{j, t}$ is described in expressions (11), (12) and (13). The evolution of $\mu_{s, t}$ is governed by the conditional transition probability matrix, $\Gamma$, the probability of becoming disabled, the optimal decision to retire, and the compulsory retirement at age 84. We assume that both

\footnotetext{
18 Recall that, for convenience, whenever we integrate the measure of households over some dimension, we drop the corresponding subscript. We also drop the first subscript whenever there are no differences between immigrants and natives.
} 
immigrants and natives enter the economy as able workers, that they do not own any assets, and that they draw the stochastic component of their initial endowment of efficiency labor units from the invariant distribution of $s$. The evolution of $\mu_{a, t}$ is determined by the optimal savings decision. Finally, the evolution of $\mu_{b, t}$ is determined by the rules of the Spanish public pension system as described in expression (2) and in the paragraph that is immediately below that expression.

\section{Calibration}

The purpose of this paper is to evaluate the aggregate, distributional and welfare consequences of delaying the retirement age in Spain taking into account both the demographic and the educational transitions. To do this, we use the following calibration strategy: First, we choose 1997 as our calibration target year. We choose 1997 because the Lorenz curves of the Spanish income and earnings distributions which are our main calibration data sources are from that year. We choose the model economy functional forms and parameters so that its main demographic, educational and economic statistics replicate as closely as possible the corresponding statistics of the Spanish economy in 1997. Then we choose an initial steady state, which we identify with the year $1950 .{ }^{19}$ The educational transition starts in 1951, the demographic transition starts in 1998 , and both transitions end in 2131. In our model economy the age and education transitions are determined by the survival probabilities, the fertility rates, and the flows of immigrants. They are exogenous and they are completely independent from the economic transitions. We have discussed the age and education transitions in detail in Díaz-Giménez and Díaz-Saavedra (2006). For the sake of brevity, even though we report them in Panels A and B of Fig. 2, we do not discuss them here. In Panel C of that same figure we report the age distributions in 1997 in Spain and in our model economy and we find that they are very similar.

\subsection{Parameters}

When all is told, to characterize our model economy fully, we must choose the values of a total of 52 parameters. Of these 52 parameters, 20 describe the government policy, 21 describe the endowment of efficiency labor units profiles, 4 describe the disability risk function, 4 describe the production technology, and the remaining 3 describe the household preferences.

\subsection{Targets}

To find the values of the 52 model economy parameters, we need 52 equations or calibration targets which we describe below.

\subsubsection{Pension system rules}

The Spanish Régimen General de la Seguridad Social, considers the last 15 years of contributions prior to retirement to compute the pension. Consequently, our choice for the number of years used to compute the retirement pensions in our model economy is $N_{b}=15$. Our choices for the minimum and maximum pensions and for the maximum covered earnings are $\underline{b}_{t}=0.33 \bar{y}_{t}, \bar{b}_{t}=1.91 \bar{y}_{t}$, and $a_{3 t}=2.59 \bar{y}_{t}$. These numbers correspond to the 1997 per capita GDP shares of average

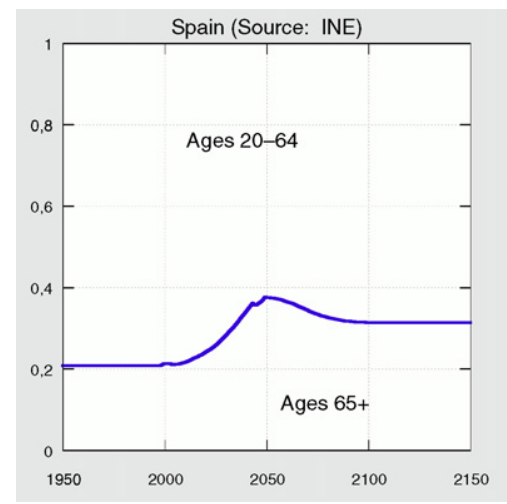

A. The age distribution.

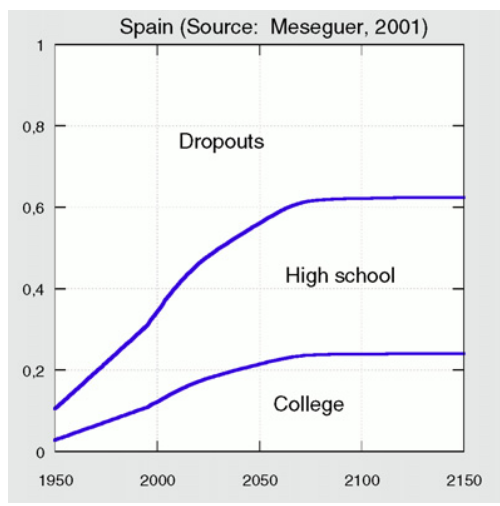

B. The educational distribution.

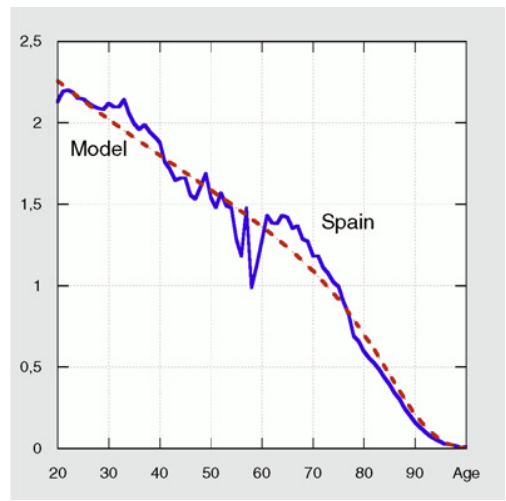

C. The population distributions.

Fig. 2. The age and educational transitions and population distributions in 1997.

19 The choice of the initial steady-state is somewhat arbitrary. We chose 1950 because it seems a reasonable starting year for the Spanish educational transition, and because it is a round number. 
minimum pensions, maximum pensions, and maximum covered earnings for workers included in the Régimen General. ${ }^{20}$ Notice that our choices for $\underline{b}_{t}$ and $\bar{b}_{t}$ also determine the values of $b_{d t}$.

In 1997 the Régimen General established that the first retirement age was 60 and that the penalty for early retirement was 8 percent for every year before age $65 .{ }^{21}$ Consequently, in our benchmark model economy we set $R_{0}=60$ and $R_{1}=65$, $a_{4}=0.4$, and $a_{5}=0.08$. Our choice for the initial value of the pension fund is $F_{2004}=0.025 Y_{2004}$. This number corresponds to the value of the Spanish pension fund at the end of 2004 according to Balmaseda et al. (2006). For the rate of return on the fund's assets we choose $r^{*}=0.02 .^{22}$

\subsubsection{Government outlays and revenues}

To choose the government policy parameters we attempt to replicate as closely as possible the 1997 Spanish Government Budget described in Table 1 . Our task is to allocate the different revenue and expenditure items reported in that table to our model economy tax instruments and government outlay items.

We choose the pension replacement rate $\phi$ in expression (2) so that the shares of pensions to output in our model economy approximates the corresponding ratio for the Spanish economy. In Spain in 1997 the sum of the shares of government consumption, gross investment and other expenditures was $22.0(=17.5+3.1+1.4)$ percent of GDP. This is the number that we target for our model economy's government expenditures to output ratio. Our targets for the model economy's nonpension transfers and interest payments are $Z / Y=0.054$ and $r D / Y=0.042$. These numbers replicate the corresponding ratios for the Spanish economy.

To identify the payroll tax function described in expression (1), we must choose the values of parameters $a_{1, t}$ and $a_{2, t}$. In Spain in 1997, the payroll tax rate paid by households was 28.3 percent and it was levied only on the first 32,700 euros of annual gross labor income. Hence, the maximum contribution was 9254 euros which correspond to 73 percent of the Spanish per capita GDP. To replicate this number, in our model economy we choose $a_{1, t}=0.73 \bar{y}_{t}$. To select a value for $a_{2, t}$, we require that the revenues collected by the payroll tax in the model economy match the 11.1 percent of output collected in the Spanish economy.

According to the Spanish Dirección General de Tributos, labor income tax revenues accounted for 79.2 percent of the individual income tax revenues in $1997 .{ }^{23}$ Since the total individual income tax revenues amounted to 7.4 percent of Spanish GDP that year, we choose the model economy labor income tax rate so that it collects $5.9(=7.4 \times 0.792)$ percent of the model economy output. We choose the model economy proportional capital income tax rate so that it collects the sum of the corporate profit taxes revenues plus the share of the personal income tax revenues not imputed to labor. Therefore, we choose the model economy labor income tax rate so that it collects $4.2(=2.7+7.4 \times 0.208)$ percent of the model economy output.

Choosing how to close the government budget has potentially important implications for policy reform evaluations. Some authors use lump-sum taxes for this purpose. We have not done so because lump-sum taxes are conspicuously absent from the current Spanish tax system. Once we have discarded lump-sum taxes we faced two options. We could have chosen to keep the government debt share of GDP constant and used the consumption tax to close the government budget. Or we could have targeted the consumption tax revenues and let the deficit vary to close the government budget. Since Spain is part of the European Monetary Union and the Spanish government is bound by the Growth and Stability pact to keep the

Table 1

Tax revenues and public expenditures in 1997

\begin{tabular}{lclr}
\hline Revenues & \%GDP & Expenditures & \%GDP \\
\hline Payroll taxes & 11.1 & Consumption & 17.5 \\
Individual income taxes & 7.4 & Pensions & 10.1 \\
Production taxes & 5.4 & Other transfers & 5.4 \\
Sales and gross receipts taxes & 5.0 & Interest payments & 4.2 \\
Corporate profit taxes & 2.7 & Gross investment & 3.1 \\
Estate taxes & 0.4 & Other expenditures & 1.4 \\
Other taxes & 0.4 & & \\
Other revenues & 6.2 & & \\
Total own revenues & 38.6 & & 41.7 \\
Deficit & 3.1 & Total expenditures & \\
Total revenues & 41.7 & &
\end{tabular}

Sources: Instituto Nacional de Estadística, and Boletín de Estadísticas Laborales 2001.

\footnotetext{
20 Specifically, in 1997 the average minimum retirement pension in Spain was 4183 euros, the maximum pension was 24,109 euros, the maximum covered earnings were 32,700 euros, and per capita GDP was 12,625 euros.

21 This rule was changed in 2002 when the first retirement age was delayed to 61, except for some special cases.

22 We also run simulations $r^{*}=0.01, r^{*}=0.03$ and $r^{*}=0.04$. The only results that vary with $r^{*}$ are the values of the pension fund. These changes are small and they do not modify the qualitative conclusions of this article.

23 The data on income tax revenues is available at http://www.meh.es/Portal/Estadistica+e+Informes/Impuestos/.
} 
debt to GDP ratio within reasonable limits, we chose the first one of these two options. Therefore, in our model economy we let the consumption tax rates vary endogenously to levy the revenues needed to satisfy the government budget. ${ }^{24}$

\subsubsection{Other targets}

We want the deterministic component of the efficiency labor unit profiles of the educational groups in our model economy, $\epsilon_{h, j}$, to approximate the corresponding profiles reported by the Instituto Nacional de Estadística in the Encuesta de Salarios en la Industria y los Servicios (2000) for the Spanish economy. Since we approximate these empirical profiles with quadratic functions, we use the data to determine the values of the nine parameters of expression (14) directly. This gives us 9 additional equations. ${ }^{25}$

We want the probability of becoming disabled to approximate the corresponding profile reported by the Boletín de Estadísticas Laborales (2002) for the Spanish economy. Since we approximate this empirical profile with an exponential function, we use the data to determine the values of parameters $a_{9}$ and $a_{10}$ in expression (15). According to the Instituto Nacional de Estadística, in 2002 in Spain 80.9 percent of the total number of people who claimed to be disabled had not completed high school, 10.4 percent had completed high school, and the remaining 8.7 percent had completed college. We use these shares to determine the values of parameters $a_{11}$ and $a_{12}$ of Eq. (16). Specifically, we set $a_{11}=0.104 / 0.809=$ 0.1285 and $a_{12}=0.087 / 0.809=0.1075$.

According to the Instituto Nacional de Estadística, in Spain in 1997 the average number of hours worked per active adult was $1308 .{ }^{26}$ If we consider the endowment of disposable time to be 14 hours per day, the total amount of disposable time is 5110 hours per year. Dividing 1308 by 5110 we obtain 25.6 percent which is the share of disposable time allocated to working in the market that we target. For the curvature of the utility function we choose $\sigma=4$. This choice and the value of the share of consumption in the utility function, imply that the relative risk aversion in consumption is 2.089 which falls within the 1.5-3 range which is standard in the literature.

Our choices for the capital income share and for the average labor productivity growth rate in our model economy are $\theta=0.375$ and $\gamma=0.006$. These are the values reported by Zabalza (1996) and by Balmaseda et al. (2006) for the Spanish economy. The model economy capital and investment to output ratios are our two additional aggregate targets. According to the BBVA database, in 1997 the value of the Spanish private capital stock was 631,430 million 1986 euros. ${ }^{27}$ According to the Instituto Nacional de Estadística in 1997 the Spanish Gross Domestic Product was 265,792 million 1986 euros. Dividing these two numbers, we obtain $K / Y=2.38$, which is our target value for the model economy capital to output ratio. For the investment to output ratio we target a value of $I / Y=18.8$ percent. This is the value reported by the Instituto Nacional de Estadística for the gross private investment to output in 1997.

We target also the two Gini indexes and six points of the Lorenz curves of the Spanish distributions of earnings and income for 1997. We have taken these measures of inequality from Budría and Díaz-Giménez (2006a), and we report them in Table 7. Castañeda et al. (2003) argue in favor of this calibration procedure to replicate the inequality reported in the data. Finally, in our model economy there are five normalization conditions. The transition probability matrix on the stochastic component of the endowment of efficiency labor units process is a Markov matrix and therefore its rows must add up to one. This property imposes three normalization conditions. We also normalize the first realization of this process to be $s(1)=1$. And we choose the initial value of the total factor productivity to be $A_{0}=1$. These normalization conditions give us 5 additional equations.

\subsubsection{Adding up}

Notice that we have specified a total of 52 equations or targets. Of these 52 targets, 20 describe the government policy, 9 the deterministic component of the endowment of efficiency labor units process, 4 the disability risk function, 2 describe the household preferences, 2 the production technology, 2 are macroeconomic aggregates, 8 are target distributional statistics, and the remaining 5 are normalization conditions. The 52 parameters and 52 targets define a full rank non-linear system of 52 equations in 52 unknowns.

\subsection{Choices}

We obtain values of 24 of the model parameters directly either because they are determined uniquely by single targets, or because they are normalization conditions. These parameters are independent of the endogenous variables of the model and we report their values in the first block of Table 2 and in Table 3. The values of 12 of the remaining parameters are determined directly by our guesses for aggregate capital and labor. We report these values in the second block of Table 2 .

To determine the values of the remaining 16 parameters, we solve the system of 16 non-linear equations in 16 unknowns obtained from imposing that the relevant statistics of the model economy should be equal to the corresponding targets.

\footnotetext{
24 Notice that unintentional bequests are endogenously determined in our model economy, and that every other expenditure and revenue item the government budget has already been targeted.

25 Since we only have data until age 64 , we estimate the quadratic functions for workers in the 20-64 age cohort and we project the resulting functions from age 65 onwards.

26 This data is available at http://www.ine.es/.

27 This number can be found at http://www.fbbva.es/TLFU/tlfu/esp/areas/econosoc/bbdd/index.jsp
} 
Table 2

Values for 32 of the model economy parameters in 1997

\begin{tabular}{llc}
\hline & Parameter & Value \\
\hline Parameters obtained directly & & \\
Number of years of contributions & $N_{b}$ & 15 \\
First retirement age & $R_{0}$ & 60 \\
Normal retirement age & $R_{1}$ & 65 \\
Maximum early retirement penalty & $a_{4}$ & 0.4000 \\
Yearly early retirement penalty & $a_{5}$ & 0.0800 \\
Pension fund rate of return & $r^{*}$ & 0.0200 \\
Probabilities of becoming disabled & & \\
& $a_{9}$ & -8.5000 \\
& $a_{10}$ & 0.1119 \\
& $a_{11}$ & 0.1285 \\
& $a_{12}$ & 0.1075 \\
Curvature of $u$ & $\sigma$ & 4.0000 \\
Capital share & $\quad$ & 0.3750 \\
Initial total factor productivity & $A_{0}$ & 1.0000 \\
Productivity growth rate & $\gamma$ & 0.0060 \\
Normalization on $s$ & $s_{1}$ & 1.0000 \\
Parameters determined by the guess for $(\boldsymbol{K}, \boldsymbol{L})$ & & \\
Payroll tax cap & $a_{1}$ & 1.5815 \\
Maximum covered earnings & $a_{3}$ & 5.5885 \\
Minimum retirement pension & $\underline{b}$ & 0.7120 \\
Maximum retirement pension & $\bar{b}$ & 4.1213 \\
Minimum disability pension & $b_{d}$ & 0.7120 \\
Initial value of the pension fund & $F_{0} / Y$ & 0.0250 \\
Labor income tax rate & $\tau_{l}$ & 0.1139 \\
Capital income tax rate & $\tau_{k}$ & 0.1851 \\
Consumption tax rate & $\tau_{c}$ & 0.2382 \\
Government consumption & $G / Y$ & 0.2070 \\
Government transfers & $Z / Y$ & 0.0541 \\
Government debt & $D / Y$ & 0.5284 \\
Parameters obtained solving the system of equations & & \\
Payroll tax rate & $a_{2}$ & 0.0654 \\
Pension replacement rate & $\phi$ & 0.5051 \\
Consumption share in $u$ & $\alpha$ & 0.3530 \\
Time discount factor & $\beta$ & 0.9895 \\
Capital depreciation rate & $\delta$ & 0.0782 \\
\hline & & \\
& &
\end{tabular}

Table 3

The deterministic component of the endowment process

\begin{tabular}{llll}
\hline & $h=1$ & $h=2$ & $h=3$ \\
\hline$a_{6, h}$ & 0.8523 & 0.6260 & 0.3950 \\
$a_{7, h}$ & 0.0821 & 0.1800 & 0.3040 \\
$a_{8, h}$ & 0.0012 & 0.0030 & 0.0047 \\
\hline
\end{tabular}

Solutions for these systems are not guaranteed to exist and, when they do exist, they are not guaranteed to be unique. Consequently, we tried many different initial values in order to find the best parameterization possible. ${ }^{28}$ We report the numerical choices for 5 of the unknowns in the third block of Table 2, and for the remaining 11 unknowns in the first two blocks of Table 4.

\section{Findings: the benchmark model economy}

\subsection{The stochastic component of the endowment process}

The procedure used to calibrate our model economy identifies the stochastic component of the endowment of efficiency labor units process, s. In Table 4 we report its main properties. We find that to replicate the Spanish Lorenz curves of the income and earnings distributions, the differences in the realizations of $s \in \mathcal{S}$ are not very large. The highest realization is only 4.3 times the lowest realization of the process. We find also that the process on $s$ is not very persistent. Specifically, the expected durations of the shocks are 2.7, 2.4, and 1.4 years. In the last column of Table 4 we report the invariant

28 To solve this system we use a standard non-linear equation solver. Specifically, we use a modification of Powell's hybrid method, implemented in subroutine DNSQ from the SLATEC package. 
Table 4

The stochastic component of the endowment process

\begin{tabular}{|c|c|c|c|c|c|}
\hline & \multirow[t]{2}{*}{ Values } & \multicolumn{3}{|c|}{ Transition probabilities } & \multirow[t]{2}{*}{$\overline{\pi^{*}(s)^{\mathrm{a}}}$} \\
\hline & & $s^{\prime}=s_{1}$ & $s^{\prime}=s_{2}$ & $s^{\prime}=s_{3}$ & \\
\hline$s=s_{1}$ & 1.0000 & 0.6300 & 0.3138 & 0.0562 & 50.42 \\
\hline$s=s_{2}$ & 3.3394 & 0.4099 & 0.5894 & 0.0007 & 45.49 \\
\hline$s=s_{3}$ & 4.3255 & 0.0000 & 0.6977 & 0.3023 & 4.09 \\
\hline
\end{tabular}

a $\pi^{*}(s) \%$ denotes the invariant distribution of $s$.

distributions of the shocks. We find that approximately 96 percent of the workers are either in state $s=s_{1}$ or in state $s=s_{2}$, and that only four percent are in state $s=s_{3}$.

\subsection{Macroeconomic aggregates and ratios in 1997}

We report the values of our aggregate targets for Spain and for the benchmark model economy in Tables 5 and 6 . In Table 5 we show that every variable is very similar in both economies. In Table 6 we show that our benchmark model economy does a good job also in replicating the main items of the 1997 Spanish government budget. The only exceptions are the consumption tax collections and the other government revenues. This is not surprising because unintentional bequests are the only "other government revenues" in our model economy, and because the consumption tax rates are determined residually to satisfy the government budget.

\subsection{Inequality in 1997}

In Table 7 we report the Gini indexes and selected points of the Lorenz curves of earnings, income, and wealth in Spain and in our benchmark model economy in 1997. We find that our model economy replicates the Spanish earnings and income distributions in very much detail. If we look at the fine print, we find that earnings is somewhat more concentrated in Spain, and that income is marginally more concentrated in the model economy. On the other hand, we find that wealth is significantly more concentrated in Spain than in our model economy. This result was expected for two reasons. First, because Díaz-Giménez and his coauthors have argued elsewhere that, in general, overlapping generations economies fail to account for the large concentrations of wealth observed in the data (see Castañeda et al., 2003). And, second, because we have not used any of the points of the Lorenz curve of wealth as part of our calibration targets and, consequently, the variance of the realizations of process $s$ is too small to generate a large concentration of wealth.

\subsection{Retirement behavior in 1997}

Perhaps the single most important feature of the Spanish economy that our model economy should approximate is the retirement behavior of Spanish households. When carrying out this comparison we must keep in mind that there are some fundamental differences between Spain and our model economy. In Spain, working-age people fall into one of five categories: employed, unemployed, retired, disabled, and other non-participants. In our model economy we only have three

Table 5

Macroeconomic aggregates and ratios in 1997 (\%)

\begin{tabular}{lllll}
\hline & $C / Y$ & $I / Y$ & $G / Y^{\mathrm{a}}$ & $K / Y^{\mathrm{b}}$ \\
\hline Spain & 59.2 & 18.8 & 22.0 & 2.38 \\
Benchmark & 59.5 & 19.8 & 20.7 & 25.6 \\
\hline
\end{tabular}

a The $G / Y$ ratio in Spain is the sum of all government outlays other than pensions, other transfers, and interest payments.

b The $K / Y$ ratio is expressed in natural units and not in percentage terms.

c Variable $h$ denotes the average share of disposable time allocated to the market.

Table 6

The government budget in 1997 (\%)

\begin{tabular}{|c|c|c|c|c|c|c|c|c|c|c|}
\hline & $G / Y^{\mathrm{a}}$ & $P / Y$ & $Z / Y$ & $I N T / Y$ & $T_{S} / Y$ & $T_{l} / Y^{\mathrm{b}}$ & $T_{k} / Y^{\mathrm{c}}$ & $\Delta D / Y$ & $E / Y^{\mathrm{d}}$ & $T_{c} / Y^{\mathrm{e}}$ \\
\hline Spain & 22.0 & 10.1 & 5.4 & 4.2 & 11.1 & 5.9 & 4.2 & 3.1 & 7.0 & 10.5 \\
\hline Benchmark & 20.7 & 11.4 & 5.4 & 4.2 & 12.2 & 5.7 & 4.3 & 3.1 & 3.2 & 13.2 \\
\hline
\end{tabular}

a In Spain this number is the sum of government consumption, government gross investment, and other government expenditures.

b In Spain this number is the labor income share of the Personal Income Tax revenues.

c In Spain this number is the sum of the Corporate Profit Tax revenues and the capital income share of the Personal Income Tax revenues.

d In Spain this number corresponds to other government revenues, and in the model economy to unintentional bequests.

e In Spain this number is the sum of the Production Tax and the Sales and Gross Receipts Taxes, and in the model economy it is obtained residually to satisfy the government budget. 
Table 7

The distributions of earnings, income and wealth in 1997

\begin{tabular}{|c|c|c|c|c|c|c|c|c|c|c|c|c|}
\hline & \multirow[t]{2}{*}{ Gini } & \multicolumn{3}{|c|}{ Bottom tail } & \multicolumn{5}{|c|}{ Quintiles } & \multicolumn{3}{|c|}{ Top tail } \\
\hline & & 1 & $1-5$ & $5-10$ & $1 \mathrm{st}$ & 2nd & $3 r d$ & 4th & 5 th & $10-5$ & $5-1$ & 1 \\
\hline \multicolumn{13}{|c|}{ The Earnings Distributions (\%) } \\
\hline Spain $^{\mathrm{a}}$ & 0.57 & 0.0 & 0.0 & 0.0 & 0.0 & 2.5 & 15.6 & 27.3 & 54.8 & 13.4 & 14.7 & 6.6 \\
\hline Benchmark & 0.54 & 0.0 & 0.0 & 0.2 & 1.1 & 3.4 & 14.7 & 28.1 & 52.5 & 13.0 & 15.3 & 5.6 \\
\hline \multicolumn{13}{|c|}{ The Income Distributions (\%) } \\
\hline Spain $^{\mathrm{a}}$ & 0.39 & 0.0 & 0.6 & 1.4 & 5.4 & 10.7 & 15.9 & 23.3 & 44.6 & 10.7 & 11.1 & 6.4 \\
\hline Benchmark & 0.40 & 0.1 & 0.7 & 1.1 & 5.0 & 10.1 & 16.1 & 23.7 & 45.1 & 11.2 & 13.3 & 4.9 \\
\hline \multicolumn{13}{|c|}{ The Wealth Distributions (\%) } \\
\hline Spain ${ }^{b}$ & 0.57 & -0.1 & 0.0 & 0.0 & 0.9 & 6.6 & 12.5 & 20.6 & 59.5 & 12.5 & 16.4 & 13.6 \\
\hline Benchmark & 0.54 & 0.0 & 0.0 & 0.0 & 0.7 & 6.0 & 14.0 & 25.3 & 54.0 & 12.9 & 15.4 & 6.4 \\
\hline
\end{tabular}

a The source of data for the Spanish income and earnings distribution is the 1997 European Community Household Panel as reported in Budría and Díaz-Giménez (2006a).

b The source of data for the Spanish wealth distribution is the 2004 Encuesta Financiera de las Familias Españolas as reported in Budría and Díaz-Giménez (2006b).

Table 8

Retirement and labor market participation in 1997

\begin{tabular}{|c|c|c|c|c|c|c|c|c|}
\hline & \multicolumn{2}{|c|}{ Avg. Ret. Ages } & \multicolumn{2}{|c|}{ \%Ret. Haz. at 60} & \multicolumn{2}{|c|}{ \%Ret. Haz. at 65} & \multicolumn{2}{|c|}{ \%Part at 60-64 } \\
\hline & Spain $^{a}$ & Model & Spain $^{b}$ & Model $^{\mathrm{c}}$ & Spain $^{b}$ & Model $^{\mathrm{C}}$ & Spain $^{d}$ & Model \\
\hline All & 60.4 & 59.6 & 29.5 & 43.8 & 85.1 & 80.4 & 28.1 & 26.5 \\
\hline Dropouts & n.a. & 58.7 & n.a. & 78.7 & n.a. & 44.2 & 25.9 & 18.9 \\
\hline High school & n.a. & 61.3 & n.a. & 16.2 & n.a. & 27.9 & 38.5 & 36.1 \\
\hline College & n.a. & 62.3 & n.a. & 5.1 & n.a. & 27.9 & 57.7 & 55.7 \\
\hline
\end{tabular}

\footnotetext{
a The Spanish data is for both males and females in 1995 (Source: Blöndal and Scarpetta, 1997).

b The Spanish data is for Spanish males in 1995. (Source: Sánchez-Martín, 2001).

c The numbers in the Education rows are the percentage shares of the retirees in each education group.

d The Spanish data is the average of the four quarters of 1997 of the Encuesta de la Población Activa.
}

of these categories: employed, retired and disabled. These differences necessarily distort our comparisons and must be kept in mind when evaluating our results.

Average retirement age. In the first column of Table 8 we report the average retirement ages. Both the Spanish and the model economy data include both the old age and the disability exits from the labor force. We find that in 1997 the average retirement age in our model economy was 59.6 years. This is only 0.8 years less than the average retirement age in the Spanish economy.

Retirement and disability hazards. In Panel A of Fig. 3 we report the probabilities of exiting the labor force due to retirement or disability conditional on being a worker at the beginning of the period. ${ }^{29}$ Two features stand out from this comparison. Qualitatively, our model economy does a fair job in replicating the general shape of the retirement and disability hazards observed in Spain, including the peaks observed at ages 60 and 65. Quantitatively, with the exception of the peak observed at age 65, the hazards between ages 60 and 69 are higher in our model economy. For instance, at age 60 the hazard in our model economy is 43.8 percent while in Spain it is only 29.5 percent.

We can think of three reasons to account for these discrepancies. First, pensions are larger in our model economy. In 1997 in our model economy pension payments accounted for 11.4 percent of output, while in Spain this number was only 10.1 percent. This is partly because in Spain there are other pension regimes who pay smaller average pensions than the Régimen General-for instance, the regime for self-employed workers. Another reason that reduces the value of working for older people in our model economy is that our replacement rate is independent of the number of years of contributions to the pension system, while in Spain the pension replacement rate is an increasing function of this number. A final reason is that in the real world the utility of leisure could be increasing with age towards the end of the life-cycle. ${ }^{30}$

Retirement and education. In the bottom rows of the second column of Table 8 we report that the average retirement ages in our model economy are increasing in the number of years of education. The average retirement ages for dropouts, high school, and college workers were 58.7, 61.3, and 62.3 years. We do not have the corresponding data for Spain, but we think that this increasing relationship is very plausible. This finding is confirmed in Panel B of Fig. 3 where we represent the retirement and disability hazards of the education groups in our model economy. Again we find that the hazards are

\footnotetext{
29 The Spanish data are reported in Sánchez-Martín (2001) and they correspond to Spanish males in 1995.

30 Gustman and Steinmeier (1986) and Jiménez-Martín and Sánchez-Martín (2007) make a similar argument.
} 


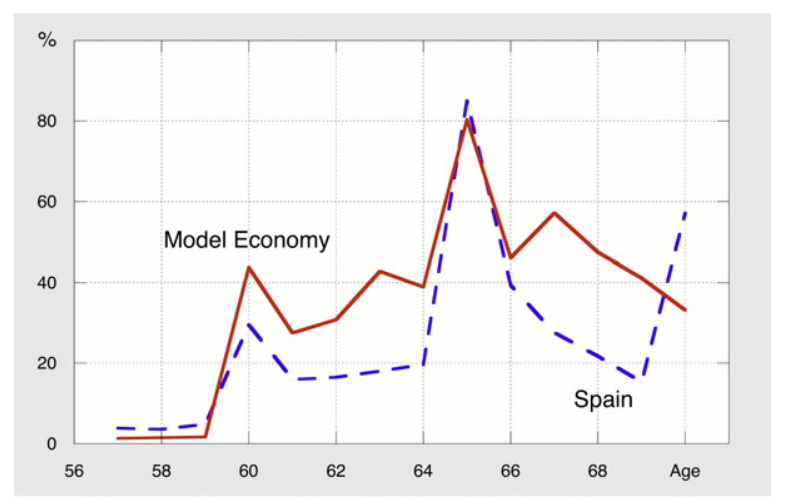

A. All households.

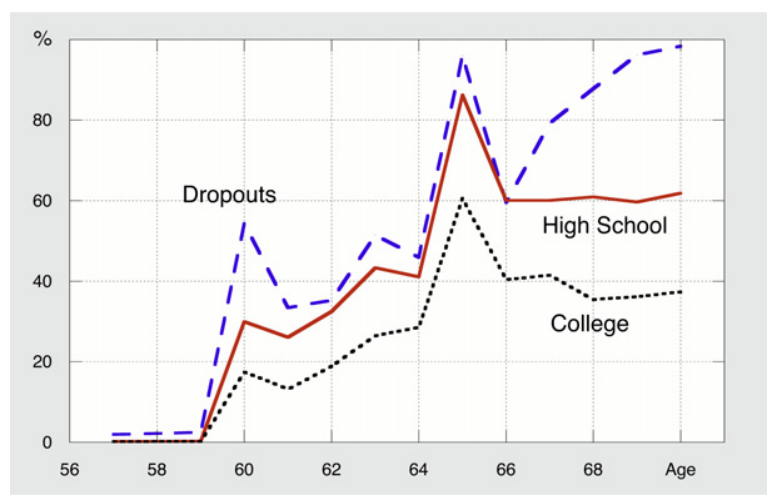

B. Education groups in the model economy.

Fig. 3. Retirement and disability hazards in 1997 (\%).

uniformly decreasing in the number of years of education. This finding was to be expected since the returns to working are increasing in the number of years of education.

In the bottom rows of the fourth and the sixth columns of Table 8 we report the educational shares of the 60 - and the 65 -year-old retirees. We find that the vast majority of the 60 -year-old retirees-79 percent-have not completed high school and that only 5 percent have completed college. At age 65 the differences in these educational shares are sizeably smaller-44 percent and 28 percent. This result is consistent with the findings of Sánchez-Martín (2001) who finds that at age 60 the probability of retiring is decreasing in the expected salary, while at age 65 this relationship is much weaker.

In the bottom rows of the last two columns of Table 8 we report the participation rates of the educational types. We take this findings with a grain of salt. This is because in our model economy we abstract from unemployment and, therefore, the employment and participation rates coincide. Still we find that the employment rates of the educational groups are similar in Spain and in our benchmark model economies, and that they are somewhat lower in our model economy. If we had modeled unemployment, the participation rates in our model economy would have been higher.

Once again we find that the participation rates of the elderly are increasing in education both in our model economy and in the data. Two reasons justify this relationship. First, many dropouts are entitled to minimum pensions only. Consequently, these workers are not affected by the early retirement penalties and they choose to retire as early as possible. And second, even though all the educational types value leisure equally, the foregone labor income-which is the opportunity cost of leisure-is smaller for less educated workers. Consequently, these workers tend to participate less than their more educated colleagues. These findings suggest that both education and minimum pensions play sizable roles in accounting for retirement behavior.

\section{Findings: delaying retirement}

We study the aggregate, distributional and welfare consequences of delaying three years the statutory retirement ages. We delay the first retirement age from 60 to 63, and the normal retirement age from 65 to 68 . Therefore, in the reformed model economy $R_{0}=63$ and $R_{1}=68$. We assume that this change is adopted in 2010 , that it was completely unexpected, and that it affects every household who had not retired by the end of 2009. To keep the distortions brought about by the reform as small as possible, and to make the comparisons meaningful, we assume that the pension system debt is financed abroad. This allows us to keep the sequences of public debt, government expenditures, transfers, capital and labor tax rates identical in both model economies. The benchmark and the reformed model economies differ only in the payroll tax collections, in the pension payments, and in the unintentional bequests, which are endogenous. And in the consumption tax rates, which we adjust to satisfy the government budget.

\subsection{Aggregate and distributional changes}

In Panel A of Fig. 4 we represent the percentage differences between the main aggregate time series of the reformed and the benchmark model economies. Our main findings are the following:

The reform is expansionary. Delaying retirement brings about a small expansion in output. In 2013, three years after the reform, output is about 1.4 percent larger in the reformed model economy and by 2060 this difference has stabilized at about 2.8 percent. As can be seen in Panel A of Fig. 4, immediately after the reform this expansion is accounted for mostly by an increase in the labor input. But after 2018 this situation is reversed and the expansion is accounted mostly by an increase in capital accumulation. In 2060 the capital and labor inputs are 3.9 and 2.4 percent larger in the reformed model economy. 


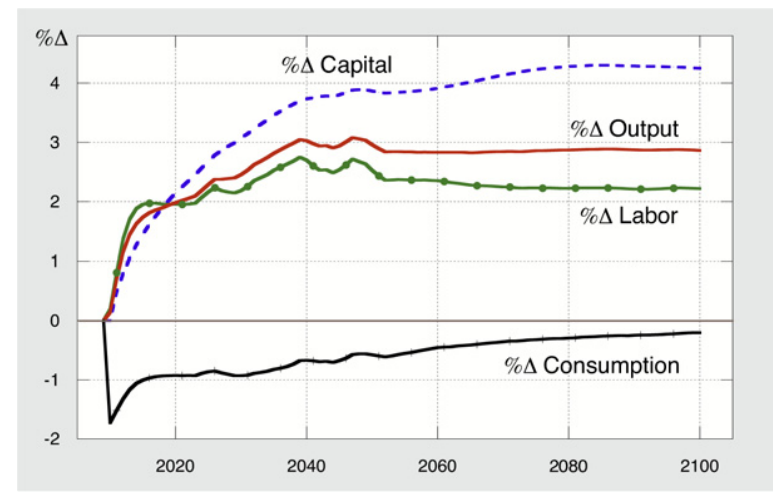

A. Diffs in output, capital, labor, and cons (\%).

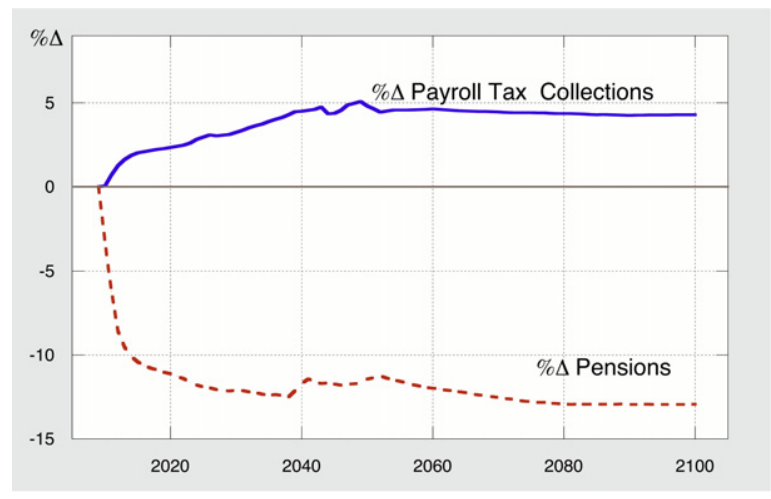

B. Diffs in payroll tax collections and pensions (\%).

Fig. 4. Aggregate differences between the benchmark and the reformed model economies.

The reform brings about a small reduction in consumption. Panel A of Fig. 4 also shows that the reform brings about a small reduction in aggregate consumption. In 2010 immediately after the reform aggregate consumption drops by 1.7 percent. And in 2060 this difference is reduced to -0.46 percent. The reduction in aggregate consumption is accounted mostly by a sizable reduction in pensions which in 2013 are already 9.5 percent smaller in the reformed model economy. See Panel C of Fig. 4.

Lower retirement pensions and higher payroll taxes. As Panel B of Fig. 4 illustrates the reform brings about a sizable reduction of pension payments. In 2013 total pension payments are 9.5 percent smaller in the reformed model economy and in 2060 they are 12.0 percent smaller. This is because the regulatory base is computed considering the last 15 years of labor earnings immediately prior to retirement and the efficiency labor units profiles decrease quite steeply after age 60. See Panel B of Fig. 1. In contrast payroll tax collections are somewhat higher in the reformed economy: 1.6 percent in 2013 and 4.6 percent in 2060. This result is consistent with the increase in labor income brought about by the reform.

The reform brings about a small increase in inequality. In 2060 the Gini indexes of earnings, income, and wealth in the benchmark model economy are $0.513,0.403$, and 0.540 . In the reformed economy these numbers are $0.519,0.410$, and 0.540. These results are partly related to the fact that after the reform less educated workers work less than their more educated colleagues. In contrast, the reform reduces the inequality of pensions. In 2060 the Gini indexes of pensions are 0.173 and 0.166 in the benchmark model and in the reformed model economies. This is because the size of the reduction in pensions is increasing in education.

\subsection{Retirement behavior}

In Panel A of Fig. 5 we plot the retirement and disability hazards in the benchmark and in the reformed model economies in 2060. And in Panel B of that same figure we plot the differences in the average retirement and disability ages. Our main findings are the following:

Delayed peaks. We find that the reform brings about sizable changes in the retirement hazards. The reform delays the first retirement age from 60 to 63. Consequently, the retirement hazards at ages 60,61 and 62 are zero and the first peak in retirement appears at age 63 . Similarly, in the reformed economy the households who retire between ages 63 and 68 must pay an early retirement penalty. This delays the second retirement peak from age 65 to age 68 .

Older retirement ages. Between 2009 and 2060 the average retirement age in our benchmark model economy is delayed by 2.2 years. The educational transition justifies this delay. Since more educated households choose to retire at older ages, as the model economy workers become more educated the average retirement age increases. ${ }^{31}$ During that same period in the reformed economy the average retirement age increases by 3.9 years. Therefore, even though the reform delays the first and the normal retirement ages by three years, the difference in the average retirement ages of the benchmark and the reformed economies in 2060 is only 1.7 years. This means that in the reformed model economy a larger number of households choose to retire early in spite of the early retirement penalties. ${ }^{32}$ Boldrin and Jiménez-Martín (2003) obtain

\footnotetext{
31 Jiménez-Martín (2006) shows that this change is already taking place in Spain. He attributes the observed increases in the participation rates of workers in the 55-64 cohort, specially of women, to the increases in the educational attainment of Spanish workers.

32 Panel A of Fig. 5 shows that the retirement hazards in the 63-68 range in the reformed economy are higher than those in the 60-65 range in the benchmark economy and it illustrates this result.
} 


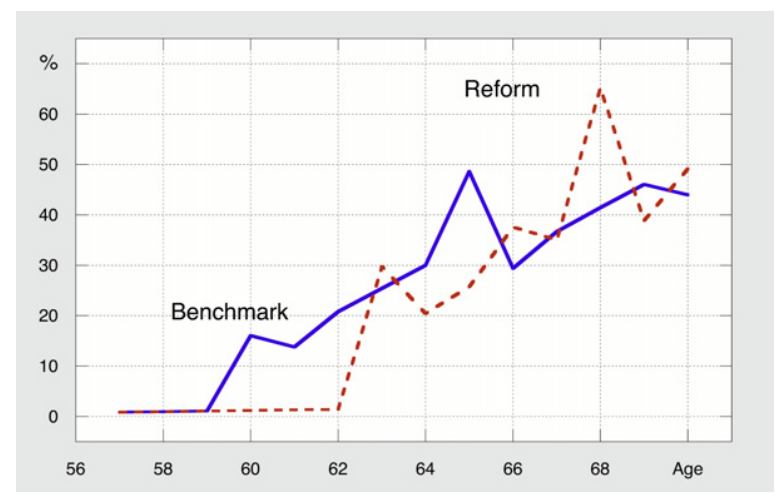

A. Retirement and disability hazards in 2060 (\%).

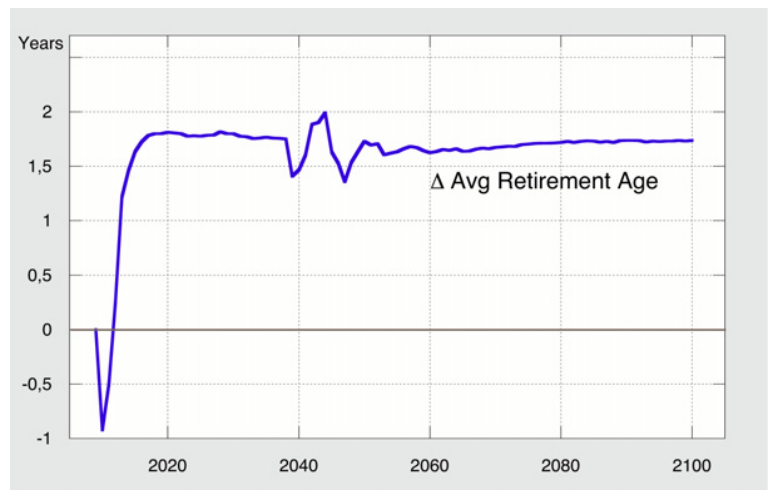

B. Diffs in the avg. retirement ages (years).

Fig. 5. Retirement behavior before and after the reform.

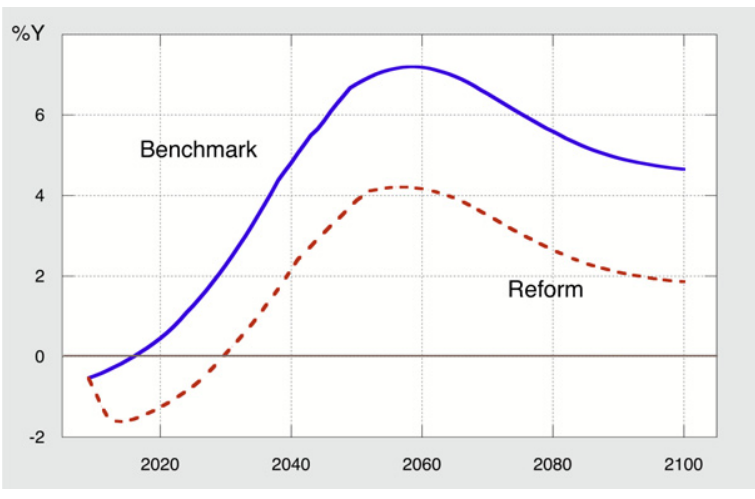

A. Pension system deficits (\%Y).

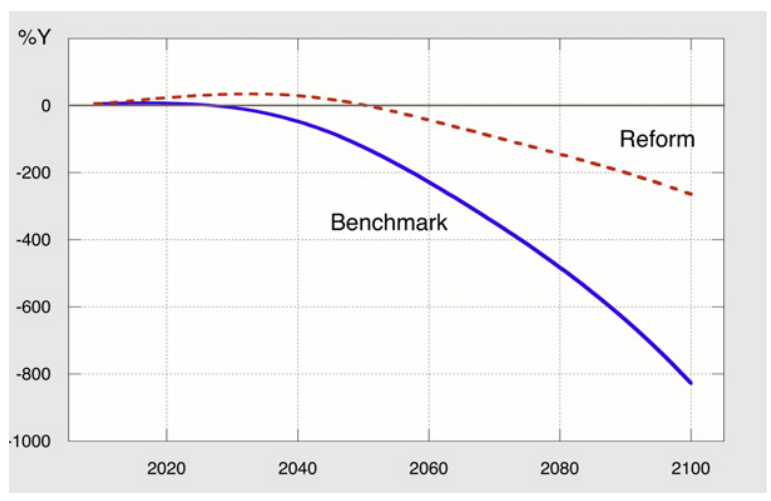

B. Pension system funds $(\% Y)$.

Fig. 6. The sustainability of the public pension system.

a similar result. ${ }^{33}$ Panel B of Fig. 5 shows that the average retirement age falls immediately after the reform. This is because the 60-, 61- and 62-year-old households who had planned to retire in 2010, cannot do so under the reform. Consequently the average retirement age in the reformed economy falls in 2010 and 2011.

\subsection{The sustainability of the public pension system}

In Panel A of Fig. 6 we represent the pension system deficits of the benchmark and the reformed model economies and in Panel B of that same figure we represent the pension system funds. Our main findings are the following:

The first deficit of the public pension system appears 14 years later under the reform. In the benchmark model economy the pension system starts running a deficit in 2016 and in the reformed economy in 2030. These differences are due to both the increase in payroll tax collections and the sizable reduction in pension payments that we have already discussed.

The public pension system is sustainable for 23 more years under the reform. In the benchmark model economy the pension system fund runs out in 2028, while in the reformed model economy it lasts until 2050. In that same year in the benchmark model economy the pension system fund is 123.4 percent of output in the red while in the reformed economy the pension system fund is about 2.3 percent of output in the black. This huge pension system debt is not to be taken too seriously. It merely illustrates that the Spanish demographic transition makes the current public pension system completely unsustainable. Something has to change before then and something will change. As we show below, in social welfare terms delaying retirement is a policy option that is worth considering.

\section{Welfare}

In the previous sections we have assumed that the government could finance the pension system deficits borrowing as much as necessary abroad, and that it only had to pay a time-invariant real interest rate of two percent to finance this bor-

\footnotetext{
33 Specifically, Boldrin and Jiménez-Martín (2003) find that the maximum of the social security wealth for an average worker covered by the Régimen General de la Seguridad Social is delayed only two years, even though the retirement ages are delayed three years. The social security wealth at age $j$ is defined as the expected present value at age $j$ of all future pension benefits.
} 


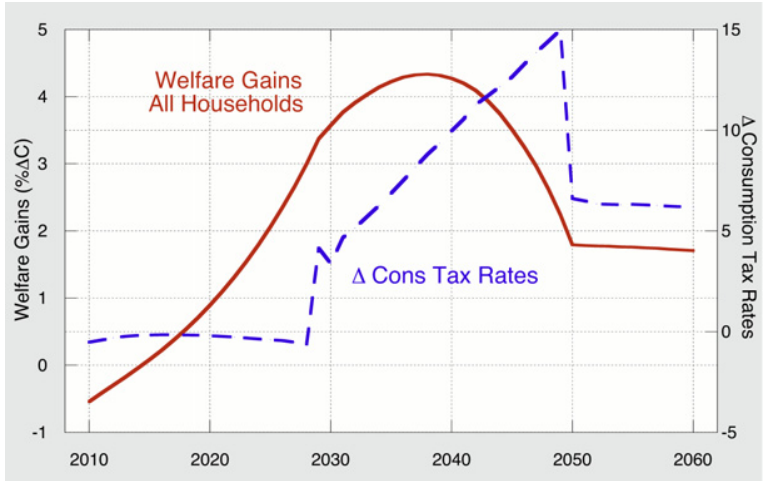

A. All households.

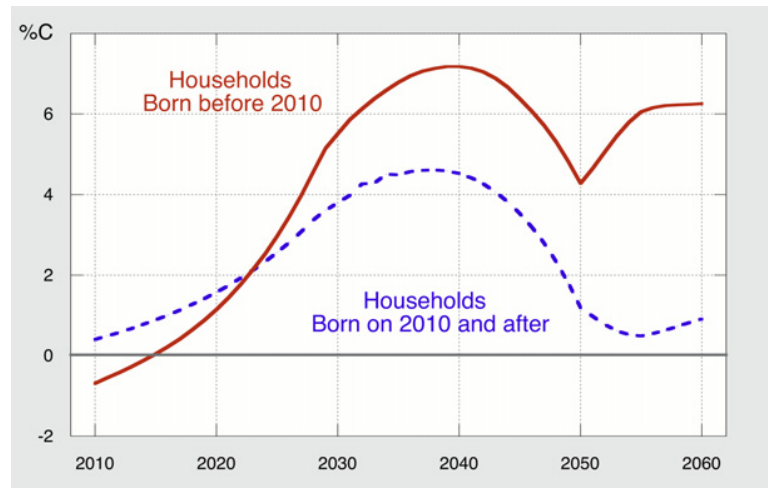

B. Per capita welfare gains.

Fig. 7. Welfare gains and consumption tax rates.

rowing. We made this choice to minimize the large distortions that the growing pension system deficits would have created if they had been financed otherwise. In some sense, this easy borrowing assumption amounts to giving the government an unrealistic free lunch. Delaying retirement in such a model economy does not create any trade-off. It decreases welfare quite trivially because average pensions and average leisure decrease. The policy recommendation in such a world would be to run a deficitary system indefinitely and never to delay retirement.

To eliminate this free lunch, in this section we evaluate the social welfare costs of delaying retirement in a model economy which is somewhat different. Instead of allowing the government to run a negative pension system fund, we assume that consumption taxes have to be raised to supplement the payroll tax collections once the pension fund is exhausted. In every other way the new benchmark model economy and the old one are identical.

Delaying retirement in this new model economy opens up an interesting margin. This is because under the current pension system rules the pension fund runs out in 2028. Consequently, in the benchmark model economy the consumption tax must be raised from 2029 onwards. In contrast, in the reformed model economy the pension fund runs out in 2049 and consumption taxes must be raised only from 2050 onwards. We plot the series of the differences in the consumption tax rates in Panel A of Fig. 7. Delaying retirement under these pension financing rules creates an interesting trade-off. The lower consumption tax rates result in welfare gains that compensate the welfare costs brought about by the reduced pensions and leisure. Which one of these two effects will dominate becomes an open question. A question that cannot be answered without computing our welfare numbers.

\subsection{Social welfare measure}

To carry out our welfare comparisons we must deal with two sets of difficulties. Our model economies are not in a steady state, and they have many different types of households. To solve these difficulties we use the following welfare measure. Let $z \in \mathfrak{R}=\mathcal{L} \times H \times J \times S \times \mathcal{A} \times B$. And define $v_{B}[z, \Delta(z)]$ as the value for of a household of type $z$ of receiving its optimal consumption allocation increased by a fraction $\Delta(z)$ each period and keeping its optimal leisure allocation unchanged between 2010 and $2060 .^{34}$ Formally,

$$
v_{B}[z, \Delta(z)]=\sum_{t=0}^{100-j} \beta^{t} \psi_{j+t, 2010+t} u\left\{c_{B 2010+t}(z)[1+\Delta(z)], 1-l_{B 2010+t}(z)\right\}
$$

where $c_{B t}(z)$ and $1-l_{B t}(z)$ are the values of consumption and leisure that solve the household decision problem in the benchmark model economy. ${ }^{35}$ Next, for each household of type $z$, we define the welfare cost of the reform as the fraction of additional consumption, $\Delta_{R}(z)$, that is needed to attain in the benchmark model economy the welfare of the reformed model economy. Formally, $\Delta_{R}(z)$ is the solution to the equation

$$
v_{B}\left[z, \Delta_{R}(z)\right]=v_{R}(z)
$$

where $v_{R}(z)$ is the value of the optimal consumption and leisure allocations between 2010 and 2060 in the reformed model economy.

\footnotetext{
34 Naturally, if a household dies before 2060 we consider the value of its optimal allocation while it is alive only.

35 We have defined this problem in expressions (18), (19), and (20).
} 
To calculate the social welfare costs of a reform in any single period of time $t$, we aggregate the individual welfare costs measured in current period consumption units as follows:

$$
w_{R t}=\int_{\Re} c(z) \Delta_{R}(z) \mathrm{d} \mu_{t} .
$$

Finally, to compute the total social welfare costs of a reform incurred during a period of years $t=0,1, \ldots, T$, we compute the present value of the single period social welfare costs using the sequence of equilibrium interest rates of the benchmark model economy as the deflators. Formally, the total social welfare cost of a reform between 2010 and 2060 is

$$
w_{R}=w_{R 2010}+\sum_{t=2011}^{2060} \frac{w_{R t}}{\prod_{j=2011}^{t}\left(1+r_{j}\right)} .
$$

We report the single period welfare costs as the percentage share of current aggregate consumption in the benchmark model economy in that period. And we report the total welfare costs as the percentage share of the present value of the flow of aggregate consumption in the benchmark model economy between 2010 and 2060.

\subsection{Social welfare changes}

It turns out that the welfare gains that result from the lower consumption tax rates more than compensate for the welfare costs that result from the reduced pensions and leisure. Delaying retirement when the government is not allowed to run a negative pension fund results in social welfare gain between 2010 and 2060 which is equivalent to 1.34 percent of the present value of its aggregate flow of consumption during those years. The households that were alive at the moment of the reform gain 0.99 percentage points, and the households that were born after the reform gain the remaining 0.35 percentage points.

The solid time series in Panel A of Fig. 7 represents the values of the social welfare gains each period expressed as a percentage of that period's aggregate consumption. In 2010, the year when the reform is enacted, the welfare gains are negative and they amount to -0.54 percent of consumption. This is mainly because of the welfare losses incurred by the households in the 51 to 65 age group who bear the brunt of the reform. Like everybody else, they are surprised by the reform. But unlike their younger colleagues, they have no time to adjust to the new retirement rules and they are forced to accept sizable reductions both in their consumption and in their leisure. After 2014 most of these people have retired and the social welfare costs become social welfare gains. The social welfare gains peak at 4.33 percent of consumption in 2038 and they stabilize around 1.7 percent after 2049. The shape of the social welfare gains curve replicates quite closely the shape of the difference in the consumption tax rates that we report in the dotted curve of the graph in Panel A of Fig. 7. It leads it by a few years as households anticipate the reduction in the consumption tax rates.

Finally in Panel B of Fig. 7 we report the per capita welfare gains of the households born before and after the reform. The dotted curve shows that the model economy households that are born after the reform prefer the life-time allocations of consumption and leisure brought about by the new pension rules and tax regimes every year between 2010 and 2060 . The gains are smallest at the beginning and at the end of this period. At the beginning because consumption taxes are higher in the reformed model economy. And at the end because the pension fund runs out and consumption taxes have to be raised. This result suggests that the Spanish demographic and educational transitions have rendered the current pension system rules undesirable because they result in too large pensions and too much leisure, given that they are financed supplementing the revenues obtained with the current payroll taxes with consumption tax revenues when the pension fund runs out.

\section{Concluding comments}

In this paper we present a state-of-the-art model economy designed to study the consequences of pension system reform. The modeling and computational advances that have taken place in recent years allow us to include so many of the relevant margins and so many of the institutional details of real economies, that we are convinced that the results of fully dynamic general equilibrium models should be given serious consideration in the political decision making process. This article is written for academic readers. Some of our data is already dated, and the reform that we study is probably too abrupt. But this does not mar our main finding: that dynamic general equilibrium methods are useful to evaluate the consequences of policy reforms. Our calibration year could be easily updated and the reform could be easily phased in gradually-for instance, we could delay the statutory retirement ages six months per year over a three year span. This would spread out the costs incurred by the households who are about to retire when the reform is implemented.

These caveats notwithstanding, we find that delaying the first and the normal retirement ages by three years is a powerful policy to solve the severe viability problems that plague the current Spanish pension system. Moreover, under the assumption that consumption taxes have to be raised to finance the pension system deficits after the pension fund is exhausted, we find that delaying retirement improves social welfare after the year 2014. This leads us to conclude that policymakers should seriously consider delaying the statutory retirement ages in Spain sometime in the near future. Naturally complementary support programs should be enacted for the households in the 51-65 age cohort to compensate them for the welfare costs that they incur during the years immediately after the reform. 


\section{Acknowledgments}

We gratefully acknowledge the financial support of the Spanish Ministerio de Ciencia y Tecnología (Grant SEJ2005-05381). We thank Juan Carlos Conesa for an early version of the code and Alfonso Sánchez-Martín for the data on the probabilities of retirement. Finally, we thank Tim Kehoe, two excellent anonymous referees and, specially, Juan Carlos Conesa and Alfonso Sánchez-Martín for many useful comments and suggestions.

\section{References}

Arjona, R., 2000. On the fiscal balance of the Spanish social security system. Estudios de Economía Española $n^{0} 78$. FEDEA, Madrid.

Balmaseda, M., Melguizo, A., Taguas, D., 2006. Las reformas necesarias en el sistema de pensiones contributivas en España. Moneda y Crédito 222, 313-340. Blöndal, S., Scarpetta, S., 1997. The retirement decision in OECD countries. Working paper $n^{0} 202$. OECD Economics Department.

Boldrin, M., Jiménez-Martín, S., 2003. Evaluating Spanish pension expenditure under alternative reform scenarios. In: Gruber, J., Wise, D. (Eds.), Social Security and Retirement Across the World: Fiscal Implications. Chicago Univ. Press, pp. 351-412.

Boletín de Estadísticas Laborales, 2002. Ministerio de Trabajo y Asuntos Sociales. http://www.mtas.es/estadisticas.

Budría, S., Díaz-Giménez, J., 2006a. Economic inequality in Spain: the European Community Household Panel Dataset. Spanish Economic Review 9, 1-38.

Budría, S., Díaz-Giménez, J., 2006b. Earnings, income and wealth inequality in Spain: La Encuesta Financiera de las Familias Españolas (EFF). Mimeo. Castañeda, A., Díaz-Giménez, J., Ríos-Rull, J.V., 2003. Accounting for the US earnings and wealth inequality. Journal of Political Economy 4, 818-855.

Conde-Ruiz, J., Galasso, V., 2003. Early retirement. Review of Economic Dynamics 6, 12-36.

Conesa, J., Krueger, D., 1999. Social security with heterogeneous agents. Review of Economic Dynamics 2, 757-795.

Cubeddu, L., 1998. The intergenerational redistributive effects of unfunded pension programs. Working paper $\mathrm{n}^{\circ} 98 / 180$. International Monetary Fund. Da-Rocha, J.M., Lores, F., 2005. ¿Es urgente reformar la seguridad social? WP 5-05. Universidad de Vigo, RGEA.

De Miguel, C., Montero, M., 2004. Envejecimiento y sostenibilidad del sistema de pensiones. Estudios de Economía Española $n^{0} 190$. FEDEA, Madrid.

De Nardi, M., İmrohoroğlu, S., Sargent, T., 1999. Projected US demographics and social security. Review of Economic Dynamics 2, 575-615.

Díaz-Giménez, J., Díaz-Saavedra, J., 2006. The demographic and educational transitions and the sustainability of the Spanish Public Pension System. Moneda y Crédito 222, 223-270.

Encuesta de Salarios en la Industria y los Servicios, 2000. Instituto Nacional de Estadística. http://www.ine.es/jaxi/menu.do?type=pcaxis\&path=/t22/

p13\&file $=$ inebase $\& N=\& L=$.

Gustman, A., Steinmeier, T., 1986. A structural retirement model. Econometrica 54, 555-584.

Hubbard, G., Judd, K., 1987. Social security and individual welfare: precautionary saving, borrowing constraints, and the payroll tax. American Economic Review 77, 630-646.

Huggett, M., Ventura, G., 1999. On the distributional effects of social security reform. Review of Economic Dynamics 2, 498-531.

İmrohoroğlu, A., İmrohoroğlu, S., Joines, D., 1995. A life cycle analysis of social security. Economic Theory 6, 83-114.

Jiménez-Martín, S., 2006. Evaluating the labor supply effects of alternative reforms of the Spanish Pension System. Moneda y Crédito 222, 271-312.

Jiménez-Martín, S., Sánchez-Martín, A., 2007. An evaluation of the life-cycle effects of minimum pensions on retirement behavior. Journal of Applied Econometrics 22, 923-950.

Jimeno, J., Rojas, J., Puente, S., 2008. Modelling the impact of aging in Social Security expenditures. Economic Modelling 25, 201-224.

Meseguer, J., 2001. Tendencias de largo plazo del sistema educativo Español y los efectos del envejecimiento. Mimeo. FEDEA.

Rojas, J., 2005. Life-cycle earnings, cohort size effects and social security: A quantitative exploration. Journal of Public Economics 89, 465-485.

Rust, J., Phelan, C., 1997. How social security and Medicare affect retirement behavior in a world of incomplete markets. Econometrica 65, 781-831.

Sánchez-Martín, A., 2001. Endogenous retirement and public pension system reform in Spain. Working paper $n^{\circ} 35 / 2001$. Universidad Carlos III de Madrid.

Zabalza, A., 1996. La recesión de los noventa en la perspectiva de los últimos treinta años de crecimiento. Moneda y Crédito 202 , 11-64. 